\title{
The Protective and Reparative Role of Colony-Stimulating Factors in the Brain with Cerebral Ischemia/Reperfusion Injury
}

\author{
Aysha Mohamed Rafik Patel ${ }^{a, b} \quad$ Nattayaporn Apaijai ${ }^{a, b} \quad$ Nipon Chattipakorn $^{a, b, c}$ \\ Siriporn C. Chattipakorn ${ }^{a}$, b, d \\ ${ }^{a}$ Neurophysiology Unit, Cardiac Electrophysiology Research and Training Center, Faculty of Medicine, Chiang Mai \\ University, Chiang Mai, Thailand; ${ }^{b}$ Center of Excellence in Cardiac Electrophysiology Research, Chiang Mai University, \\ Chiang Mai, Thailand; 'C Cardiac Electrophysiology Unit, Department of Physiology, Faculty of Medicine, Chiang Mai \\ University, Chiang Mai, Thailand; ${ }^{d}$ Department of Oral Biology and Diagnostic Sciences, Faculty of Dentistry, Chiang Mai \\ University, Chiang Mai, Thailand
}

\section{Keywords \\ Colony-stimulating factors $\cdot$ Ischemia $\cdot$ Reperfusion $\cdot$ Brain injury}

\begin{abstract}
Stroke is a debilitating disease and has the ability to culminate in devastating clinical outcomes. Ischemic stroke followed by reperfusion entrains cerebral ischemia/reperfusion (I/R) injury, which is a complex pathological process and is associated with serious clinical manifestations. Therefore, the development of a robust and effective poststroke therapy is crucial. Granulocyte colony-stimulating factor (GCSF) and erythropoietin (EPO), originally discovered as hematopoietic growth factors, are versatile and have transcended beyond their traditional role of orchestrating the proliferation, differentiation, and survival of hematopoietic progenitors to one that fosters brain protection/neuroregeneration. The clinical indication regarding GCSF and EPO as an auspicious therapeutic strategy is conferred in a plethora of illnesses, including anemia and neutropenia. EPO and GCSF alleviate cerebral I/R injury through a multitude of mechanisms, involving antiapoptotic, anti-inflammatory, antioxidant, neurogenic, and angiogenic effects. Despite bolstering
\end{abstract}

evidence from preclinical studies, the multiple brain protective modalities of GCSF and EPO failed to translate in clinical trials and thereby raises several questions. The present review comprehensively compiles and discusses key findings from in vitro, in vivo, and clinical data pertaining to the administration of EPO, GCSF, and other drugs, which alter levels of colony-stimulating factor (CSF) in the brain following cerebral I/R injury, and elaborates on the contributing factors, which led to the lost in translation of CSFs from bench to bedside. Any controversial findings are discussed to enable a clear overview of the role of EPO and GCSF as robust and effective candidates for poststroke therapy.

๑) 2020 S. Karger AG, Basel

\section{Introduction}

Stroke is a debilitating heterogeneous syndrome and one of the leading causes of mortality and disability worldwide. Broadly, stroke can be classified into 2 types: hemorrhagic and ischemic strokes, the latter of which accounts for $87 \%$ of stroke cases [1]. Globally, 13.7 million individuals are affected by stroke per year [2]. Thus, the societal and economic burdens of stroke remain. Ideally, karger@karger.com

(c) 2020 S. Karger AG, Basel

www.karger.com/nen

Karger!
Siriporn C. Chattipakorn

Neurophysiology Unit, Cardiac Electrophysiology Research and Training Center Faculty of Medicine, Chiang Mai University

Intavaroros Rd. Sriphum Muang, Chiang Mai 50200 (Thailand)

scchattipakorn@gmail.com 
cerebral ischemia, whether focal or global in nature, is followed by reperfusion, the subsequent vascular restoration and reoxygenation. Despite the advantageous restorative effects of reperfusion, a considerable amount of literature has established the deleterious effects of rapid reperfusion, which thereby entrains the phenomenon known as cerebral ischemia/reperfusion (I/R) injury.

At present, thrombolysis or mechanical thrombectomy is deemed an effective therapeutic strategy to initiate reperfusion in ischemic stroke. Currently, the primary criterion for reperfusion therapy is the time from stroke symptom onset. Reperfusion therapy must be administered within a narrow window of time, for instance, intravenous tissue plasminogen activator (tPA) must be given up to $4.5 \mathrm{~h}$ after symptom onset. Therefore, this time restriction disqualifies the majority of stroke patients admitted beyond this narrow time window (around 85\%), thereby drastically limiting the eligible population [3-5].

Rapid reperfusion abolishes the advantageous effects of reestablishing blood flow due to oxidative stress, mitochondrial dysregulation, leukocyte infiltration, bloodbrain barrier (BBB) disruption, brain inflammation, and increased neuronal apoptosis, ultimately leading to infarction and subsequent cognitive impairments [6]. Regrettably, there is not yet an effective therapeutic tool to ameliorate the repercussions of cerebral I/R and understanding the sheer complexity of the injury cascade is crucial for the development of improved treatments.

Colony-stimulating factors (CSFs) are fast being acknowledged to play a pivotal role in alleviating cerebral $\mathrm{I} / \mathrm{R}$ injury, and their biological activity is now known to not be exclusive to the hematopoietic system [7]. Hematopoietic CSFs are cytokines that play a crucial role in cell survival, proliferation, and differentiation of progenitors, as well as functional activation of mature cells [7]. Moreover, the administration of CSFs through their pleiotropic effect activates a multitude of processes, which include stem cell survival, enhanced angiogenesis, and neurogenesis coupled with antiapoptotic and anti-inflammatory effects [8]. In reviewing literature, several pharmacological agents, including ligustilide and salidroside, not only alleviated cerebral I/R injury but also upregulated the expression of CSF and CSF receptors in the brain [9-18]. Additionally, erythropoietin (EPO) and granulocyte colony-stimulating growth factor (GCSF) are the most prominent CSFs, which have been thoroughly investigated for the treatment of cerebral I/R injury.

$\mathrm{EPO}$, a $30.4-\mathrm{kDa}$ glycoprotein and hypoxia-inducible hematopoietic factor, promotes cell proliferation, differentiation, and survival of erythroid progenitors. EPO is routinely used to treat anemia in patients with ESRD and cancer [19]. GCSF, a 19.6-kDa glycoprotein, is involved in the mobilization and maturation of bone marrow-derived cells. GCSF is widely used to treat chemotherapyinduced neutropenia and enhances stem cell mobilization in bone marrow transplantation [20]. The observation of EPO and GCSF in the brain has sparked enthusiasm for further investigation, which has transcended their role broadly beyond hematopoiesis to critical neuroprotectants in a host of disorders including cerebral ischemia. EPO and GCSF prove to be candidates for neuroprotectants in stroke therapy; yet, the comprehensive mechanistic insight regarding the protective effect in the brain remains obscure. Despite the bolstering evidence from preliminary clinical studies, EPO and GCSF administration did not prove effective in alleviating ischemic damage in stroke patients; this discrepancy could be attributed to a number of causes, which will be discussed extensively in the following review.

Overall, the existing body of research suggests exogenous EPO or GCSF to be either an auspicious or a detrimental therapeutic strategy in cerebral I/R injury; this discordance can be due to a plethora of causes, including type of ischemia, duration of ischemia, duration of reperfusion, CSF dosage, route of administration, duration of treatment, interaction with other drugs, and whether it is pre-, post-, or during ischemia. The purpose of this review is to comprehensively compile and discuss the key findings from in vitro, in vivo, and clinical studies with regard to the administration of CSFs, in particular EPO and GCSF, in the brain following cerebral I/R injury and address any contradictory findings.

\section{The Role of CSFs and CSF/R in the Brain under the Physiological Condition}

A growing body of literature addresses the role of several CSFs, such as macrophage colony-stimulating factor (CSF1), granulocyte-macrophage colony-stimulating factor (GMCSF/CSF2), GCSF (CSF3), EPO, and thrombopoietin, in the brain. Moreover, CSFs bind to specific corresponding cytokine receptors (e.g., CSF1/R, CSF2/R, and CSF3/R) activating several signaling pathways and thereby initiating cell proliferation/differentiation and antiapoptotic and anti-inflammatory effects. CSF1/R signaling directly controls the development and maintenance of microglia, resident macrophages in the brain; therefore, inhibition of CSF1/R depleted microglia and thereby exacerbated brain inflammation and stroke se- 


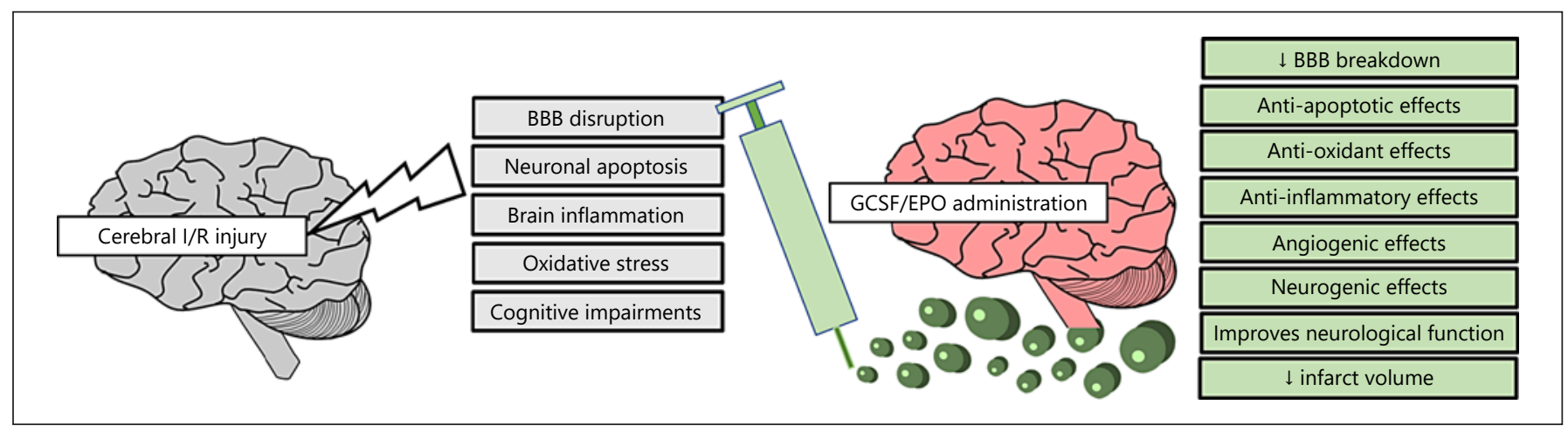

Fig. 1. The deleterious effects of cerebral ischemia/reperfusion (I/R) injury on the brain, and the neuroprotective effects of erythropoietin (EPO)/ granulocyte colony-stimulating factor (GCSF) on the brain following cerebral $\mathrm{I} / \mathrm{R}$ injury. Cerebral I/R injury causes mitochondrial dysregulation, oxidative stress/reactive oxygen species (ROS), leukocyte infiltration, blood-brain barrier (BBB) disruption, brain inflammation, and increased neuronal apoptosis, ultimately leading to infarction and subsequent cognitive impairments. EPO and GCSF alleviate cerebral I/R injury.

verity due to the inability to inhibit the ischemia-induced astrocyte response [21].

GCSF is involved in the mobilization and maturation of bone marrow-derived cells [20]. Notably, GCSF and GCSF/R are co-expressed by neurons in the hippocampus CA3 field, the hilus, subgranular zone of the dentate gyrus, entorhinal cortex, olfactory bulb, and several cerebellar and brainstem nuclei [22]. To a lesser extent, GCSF/R may also be present on glial cells [22]. Thus, it can be inferred that GCSF serves as an autocrine protective signaling mechanism [22]. In several experimental studies of cerebral ischemia, exogenous GCSF effectively penetrated the $\mathrm{BBB}$ and exerted brain protection by hematopoietic stem cell mobilization, neuronal differentiation, and antiapoptotic, angiogenic, and anti-inflammatory effects.

EPO promotes proliferation, differentiation, and survival of erythroid progenitors. The physiological function of EPO extends broadly beyond erythropoiesis as the erythropoietin receptor (EPO/R), and EPO is functionally expressed by neuronal, glial, and endothelial cells of the central nervous system [23]. The powerful mechanism of ischemic preconditioning protects the brain from subsequent, prolonged, and lethal ischemia in rats and is reliant on EPO upregulation in the tissue penumbra [24]. $\mathrm{EPO}$ and $\mathrm{EPO} / \mathrm{R}$ expression is regulated by hypoxia-inducible factor 1 (HIF-1) or other members of the family, HIF- $1 \alpha$, HIF- $1 \beta$ and HIF- $3 \alpha$, which are activated by a range of stressors to foster protection against hypoxic cell injury [23]. EPO is mainly produced and secreted in the hippocampus, internal capsule, cortex, midbrain, cere-

CSFs and Cerebral I/R Injury bral endothelial cells, and astrocytes [25]. The role of EPO has transcended from merely keeping up oxygen saturation in tissues to a critical neuroprotectant in cerebral ischemia. EPO limits the production of tissue-injuring molecules such as reactive oxygen species (ROS) and glutamate, modulates neurotransmission, stimulates angiogenesis, attenuates apoptosis, modulates inflammation, and recruits stem cells [26].

Pharmacological drugs, such as etifoxine, also alleviate cerebral I/R injury by CSF $1 / R$ activation, and inhibiting CSF1/R abolished brain protective effects [27]. Thus, it can be assumed CSF1/R signaling plays a critical role in brain ischemia. Additionally, several pharmacological agents exerted brain protective effects against cerebral I/R injury partially by increasing the expression of EPO induced by HIF-1 [9-16] or the upregulation of GCSF or GMCSF expression [17]. Moreover, extensive research has recognized the critical role of stimulating GCSF/R and $\mathrm{EPO} / \mathrm{R}$ to alleviate cerebral I/R injury in rats. Therefore, the following paragraphs will summarize and discuss all findings regarding GCSF, EPO, and corresponding receptors in cerebral I/R injury. The beneficial effects of GCSF and EPO on the brain following cerebral I/R injury are summarized in Figure 1.

\section{The Role of Endogenous CSF in Stroke Outcome}

Endogenous EPO and GCSF play a crucial role in the brain's response to ischemia. A clear demonstration of the role of endogenous GCSF and EPO in response to 
ischemia comes from the detection that GCSF- or EPOdeficient mice are prone to develop larger infarcts and have worse neurological outcomes, and these adverse effects are reversed upon GCSF or EPO administration, respectively $[28,29]$. GCSF deficiency resulted in an upregulation of matrix metalloproteinase (MMP)-9 in the direct peri-ischemic tissue. Therefore, GCSF-mediated suppression of MMP-9 further demonstrates that endogenous GCSF plays a significant role in brain protective mechanisms [28]. Additionally, EPO/R-deficient mice showed an increased sensitivity to hypoxia and increased brain apoptosis [28], and EPO inhibition resulted in more severe brain damage [30]. The pronounced upregulation of $\mathrm{EPO} / \mathrm{EPO} / \mathrm{R}$ and GCSF/GCSF/R in human ischemic/ hypoxic brains underlines their role as endogenous brain protective systems and suggests novel therapeutic potential in cerebrovascular disease for EPO and GCSF, clinically well-characterized and safe compounds.

\section{The Effects of GCSF on Neurological Function and Infarct Volume following Cerebral I/R Injury}

Neurological deficits and infarct volume are the possible sequelae after cerebral $\mathrm{I} / \mathrm{R}$ injury. In some cases, neuronal damage has been observed in the CA1 layer of the hippocampus, resulting in learning, memory, and spatial deficits [31]. Consequently, there is a diverse range of neurological tests and scales, which serve as valuable tools to quantify and evaluate neurological deficits; commonly used is the modified neurological severity score (mNSS) scale, which is a composite score of motor, sensory, reflex, and balance tests [32].

GCSF administration during ischemia [33], at the onset of ischemia [34], and after reperfusion [22, 35-43] as a single- or multiple-dose regimen $[36,40]$ exerted brain protective properties in rats with cerebral I/R injury at doses varying between $10 \mu \mathrm{g} / \mathrm{kg}$ and $15 \mathrm{mg} / \mathrm{kg}$ [22, 3343]. The delayed administration of a low dose of human recombinant GCSF (rhGCSF) $(10 \mu \mathrm{g} / \mathrm{kg}) 5 \mathrm{~h}$ after middle cerebral artery occlusion (MCAO) and for an additional 5 days exhibited a lesser impact on infarct volume but ameliorated neurological function and increased survival rate compared to the vehicle-treated group [38]. Alternatively, several studies demonstrate GCSF administration at the dose $50 \mu \mathrm{g} / \mathrm{kg}$ at the onset of ischemia [34] or after reperfusion [35-37, 39, 40] effectively reduced infarct volume and attenuated neurological deficits in rats with cerebral I/R injury. In a similar manner, GCSF administration at the dose $60 \mu \mathrm{g} / \mathrm{kg}[22,41]$ after reperfusion, 200 $\mu \mathrm{g} / \mathrm{kg}$ during ischemia [33], and $15 \mathrm{mg} / \mathrm{kg}$ given $1 \mathrm{~h}$ after reperfusion [42] exerted advantageous brain protective effects on rats with cerebral I/R injury. A conclusive experimental dose finding from a singular study is not available. However, the dose-response relationship of GCSF is well established, a higher dose of GCSF is associated with significantly smaller infarct size and improved neurological score [44].

In view of all that has been mentioned so far, one may suppose that the administration of GCSF during ischemia, at the onset of ischemia, and after reperfusion, for the most part, attenuated neurological deficits and effectively reduced infarct volume. Moreover, GCSF administration not only reduced neurological deficits in the acute phase but also improved long-term functional outcome $[35,36]$. However, a note of caution is due here, as the aforementioned studies subtly differ in cerebral I/R models due to the selected duration of ischemia.

Existing research recognizes the critical role played by hypothermia to treat cerebral I/R injury. However, a relatively small body of literature has addressed GCSF with hypothermia as a potential poststroke therapy. The combined treatment of GCSF after reperfusion with mild hypothermia $\left(33.5-35^{\circ} \mathrm{C}\right)$ provided greater efficacy in reducing neurological deficits and infarct volume than either GCSF or hypothermia alone [42]. This study confirms GCSF and hypothermia alone have the ability to alleviate the repercussions of cerebral I/R injury; however, the major finding is that the combined treatment of hypothermia and GCSF is more effective, as hypothermia may provide the beneficial effect for the recovery of stroke patients by decreasing edema and GCSF may protect neurons from apoptosis [42]. Thus, future study of the combined treatment of GCSF with other promising therapeutic strategies is therefore recommended.

To date, a considerable amount of literature has evaluated the impact of a multiple-dose regimen of GCSF to treat cerebral I/R injury. Accordingly, Solaroglu et al. [34] demonstrated a single dose of GCSF in rats reduced infarct volume $24 \mathrm{~h}$ after $\mathrm{MCAO}$, and similar findings were observed $72 \mathrm{~h}$ after MCAO when GCSF was administered for an additional 2 days along with the advantageous outcome of tissue preservation 2 weeks after treatment.

GCSF administered at the dose $50 \mu \mathrm{g} / \mathrm{kg}$ was efficacious in a plethora of cerebral I/R models. Worthy of note, however, a hypodermic injection of GCSF after reperfusion in either short-acting form over 5 days or longacting form by a single dose similarly reduced infarct volume and gradually improved neurological function; however, the mNSS score showed no significant improvement 
Table 1. The effects of GCSF on neurological function and infarct volume in the brain following cerebral I/R injury: reports from in vivo studies

\begin{tabular}{|c|c|c|c|c|c|}
\hline \multirow{2}{*}{$\begin{array}{l}\text { Model/I/R } \\
\text { protocol }\end{array}$} & \multirow{2}{*}{$\begin{array}{l}\text { Intervention/dose/duration/ } \\
\text { route of administration }\end{array}$} & \multicolumn{2}{|c|}{ Major findings } & \multirow[t]{2}{*}{ Interpretation } & \multirow[t]{2}{*}{ Ref } \\
\hline & & $\begin{array}{l}\text { infarct } \\
\text { volume }\end{array}$ & neurological function & & \\
\hline $\begin{array}{l}\mathrm{SD} \text { rats/tMCAO/ } \\
90 \mathrm{~min} / 24 \mathrm{~h} \text { and up } \\
\text { to } 2 \text { weeks }\end{array}$ & $\begin{array}{l}\mathrm{GCSF} / 50 \mu \mathrm{g} / \mathrm{kg} / \text { onset of } \\
\text { ischemia/SC versus vehicle } \\
\mathrm{GCSF} / 50 \mu \mathrm{g} / \mathrm{kg} / \text { Onset } \\
\text { reperfusion and additional } 2 \\
\mathrm{~d} / \text { s.c. versus vehicle }\end{array}$ & $\begin{array}{l}\downarrow(24 \mathrm{~h}) \\
\downarrow(72 \mathrm{~h})\end{array}$ & $\begin{array}{l}- \\
-\end{array}$ & $\begin{array}{l}\text { A single dose of GCSF administered at } \\
\text { the onset of ischemia and multiple } \\
\text { doses of GCSF administered at the } \\
\text { onset of reperfusion preserved tissue } \\
\text { and reduced infarct volume and } \\
\text { neurological deficits in rats with } \\
\text { cerebral I/R injury }\end{array}$ & {$[34]$} \\
\hline $\begin{array}{l}\text { Wistar rats/tMCAO/ } \\
90 \mathrm{~min} / 7 \text { or } 28 \mathrm{~d}\end{array}$ & $\begin{array}{l}\mathrm{GCSF} / 50 \mathrm{U} / \mathrm{kg} / \text { single dose at } \\
\text { onset of reperfusion } / \mathrm{s.c} \text {. versus } \\
\text { vehicle }\end{array}$ & $\begin{array}{l}\downarrow \\
\text { (Day 7) }\end{array}$ & - & $\begin{array}{l}\text { GCSF administration at the onset of } \\
\text { reperfusion reduced infarct volume in } \\
\text { rats with cerebral I/R injury }\end{array}$ & {$[40]$} \\
\hline $\mathrm{SD}$ rats $/ \mathrm{tMCAO} /-/ 5 \mathrm{~d}$ & $\begin{array}{l}\text { Short-acting GCSF/50 } \mu \mathrm{g} / \mathrm{kg} / 1 \mathrm{~h} \\
\text { after reperfusion, and daily for } 5 \\
\mathrm{~d} / \mathrm{s} . c \text {. versus vehicle } \\
\text { Long-acting GCSF/50 } \mu \mathrm{g} / \mathrm{kg} / \\
\text { single injection at } 1 \mathrm{~h} \text { after } \\
\text { reperfusion/s.c. versus vehicle }\end{array}$ & $\downarrow$ & $\begin{array}{l}\downarrow \text { NSS } \\
\text { (Days 3, 4, and 5) }\end{array}$ & $\begin{array}{l}\text { Short- and long-acting GCSF } \\
\text { administration after reperfusion } \\
\text { similarly reduced infarct volume and } \\
\text { neurological deficits }\end{array}$ & {$[43]$} \\
\hline $\begin{array}{l}\mathrm{SD} \text { rats/MCAO/ } \\
30 \mathrm{~min} / 1,2,3,7 \\
\text { and } 14 \mathrm{~d}\end{array}$ & $\begin{array}{l}\mathrm{GCSF} / 200 \mu \mathrm{g} / \mathrm{kg} / \mathrm{during} \\
\text { ischemia/s.c. versus vehicle } \\
\mathrm{L}-\mathrm{NAME} / 30 \mathrm{mg} / \mathrm{kg} / 30 \mathrm{~min} / \\
\text { before } \mathrm{I} / \mathrm{R}+\mathrm{GCSF} / \mathrm{i} . \mathrm{p} \text {. versus } \\
\text { GCSF }\end{array}$ & $\downarrow$ & $\begin{array}{l}\downarrow \text { mNSS } \\
(\text { days } 1,2,3,7 \text {, and } 14 \text { ) } \\
\uparrow \text { mNSS } \\
\text { (days } 1,2,3,7 \text {, and } 14 \text { ) }\end{array}$ & $\begin{array}{l}\text { GCSF administration during ischemia } \\
\text { decreased infarct volume and } \\
\text { neurological deficits in rats with } \\
\text { cerebral I/R injury }\end{array}$ & {$[33]$} \\
\hline $\begin{array}{l}\mathrm{SD} \text { rats/MCAO/1 h/ } \\
7,14 \text {, and } 21 \mathrm{~d}\end{array}$ & $\begin{array}{l}\mathrm{rhGCSF} / 10 \mu \mathrm{g} / \mathrm{kg} / \mathrm{d} / \mathrm{daily} \text { for } 5 \\
\mathrm{~d} / 5 \mathrm{~h} \text { after reperfusion/s.c. versus } \\
\text { vehicle }\end{array}$ & $\leftrightarrow$ & $\begin{array}{l}\downarrow \text { NSS score } \\
\uparrow \text { Survival rate }\end{array}$ & $\begin{array}{l}\text { rhGCSF administration after } \\
\text { reperfusion improved the survival rate } \\
\text { and reduced neurological deficits in } \\
\text { rats with cerebral I/R injury }\end{array}$ & {$[42]$} \\
\hline $\begin{array}{l}\text { EGFP-BM chimera } \\
\text { mice/tMCAO/ } 60 \mathrm{~min} / \\
24 \text { or } 72 \mathrm{~h}\end{array}$ & $\begin{array}{l}\mathrm{rhGCSF} / 50 \mu \mathrm{g} / \mathrm{kg} / 30 \mathrm{~min} \text { after } \\
\text { ischemia/intravascular versus } \\
\text { vehicle }\end{array}$ & $\downarrow$ & $\begin{array}{l}\downarrow \text { Neurological deficit (24 and } \\
72 \mathrm{~h} \text { ) }\end{array}$ & $\begin{array}{l}\text { rhGCSF administration after ischemia } \\
\text { reduced infarct volume and } \\
\text { neurological deficits in rats with } \\
\text { cerebral I/R injury }\end{array}$ & {$[38]$} \\
\hline $\begin{array}{l}\mathrm{SD} \text { rats/tMCAO/ } \\
90 \mathrm{~min} / 4 \text { or } 7 \mathrm{~d}\end{array}$ & $\begin{array}{l}\text { rhGCSF/50 } \mu \mathrm{g} / \mathrm{kg} / 2 \mathrm{~h} / 3 \\
\text { consecutive days i.p. versus } \\
\text { vehicle } \\
\mathrm{rhGCSF} / 50 \mu \mathrm{g} / \mathrm{kg} / 1 \mathrm{~d} / 3 \\
\text { consecutive days i.p. versus } \\
\text { vehicle } \\
\mathrm{rhGCSF} / 50 \mu \mathrm{g} / \mathrm{kg} / 4 \mathrm{~d} / 3 \\
\text { consecutive days i.p. versus } \\
\text { vehicle } \\
\text { rhGCSF/50 } \mu \mathrm{gg} / \mathrm{kg} / 7 \mathrm{~d} / 3 \\
\text { consecutive days i.p. versus } \\
\text { vehicle }\end{array}$ & - & $\begin{array}{l}\uparrow \text { Rotarod test (at } 14,21,28, \\
\text { and } 35 \text { d) } \\
\downarrow \text { MLPT (at } 1,7,21 \text {, and } 28 \mathrm{~d} \text { ) } \\
\uparrow \text { Rotarod test (at } 14,21,28, \\
\text { and } 35 \text { d) } \\
\downarrow \text { MLPT (at } 7,21 \text {, and } 28 \text { d) } \\
\uparrow \text { Rotarod test (at } 21,28 \text {, and } \\
35 \text { d) } \\
\downarrow \text { MLPT (at } 7,21 \text {, and } 28 \text { d) } \\
\uparrow \text { Rotarod test (at } 21,28 \text {, and } \\
35 \text { d) } \\
\leftrightarrow \text { MLPT }\end{array}$ & $\begin{array}{l}\text { rhGCSF administration after ischemia } \\
\text { reduced infarct volume and } \\
\text { neurological deficits in rats with } \\
\text { cerebral I/R injury }\end{array}$ & {$[39]$} \\
\hline $\mathrm{SD}$ rats/MCAO/90 min & $\begin{array}{l}\mathrm{rhGCSF} / 60 \mu \mathrm{g} / \mathrm{kg} / 2 \mathrm{~h} \text { after onset } \\
\text { of ischemia } / 20 \mathrm{~min} \text { i.v. versus } \\
\text { vehicle }\end{array}$ & $\downarrow$ & $\begin{array}{l}\downarrow \text { Mortality } \\
\uparrow \text { Rotarod } \\
\downarrow \text { NSS } \\
\downarrow \text { Adhesive tape removal } \\
- \text { contralateral }\end{array}$ & $\begin{array}{l}\text { rhGCSF administration in a delayed } \\
\text { fashion, after onset of ischemia, } \\
\text { reduced infarct volume and improved } \\
\text { long-term behavioral outcome in rats } \\
\text { with cerebral I/R injury }\end{array}$ & {$[22]$} \\
\hline $\begin{array}{l}\mathrm{SHR} \text { rats/MCAO/ } 60 \\
\mathrm{~min} / 24,72 \mathrm{~h}\end{array}$ & $\begin{array}{l}\mathrm{GCSF} / 60 \mu \mathrm{g} / \mathrm{kg} / \mathrm{s.c} .+\mathrm{tPA} / 10 \\
\mathrm{mg} / \mathrm{kg} / 5 \mathrm{~h} \text { after reperfusion } \\
\text { versus vehicle }\end{array}$ & $\begin{array}{l}\downarrow \\
(72 \mathrm{~h})\end{array}$ & - & $\begin{array}{l}\text { Combined treatment of GCSF and } \\
\text { tissue plasminogen activator } \\
\text { administered after reperfusion reduced } \\
\text { infarct volume in rats with cerebral I/R } \\
\text { injury }\end{array}$ & {$[36]$} \\
\hline
\end{tabular}


Table 1 (continued)

\begin{tabular}{|c|c|c|c|c|c|}
\hline \multirow{2}{*}{$\begin{array}{l}\text { Model/I/R } \\
\text { protocol }\end{array}$} & \multirow{2}{*}{$\begin{array}{l}\text { Intervention/dose/duration/ } \\
\text { route of administration }\end{array}$} & \multicolumn{2}{|c|}{ Major findings } & \multirow[t]{2}{*}{ Interpretation } & \multirow[t]{2}{*}{ Ref } \\
\hline & & $\begin{array}{l}\text { infarct } \\
\text { volume }\end{array}$ & neurological function & & \\
\hline $\begin{array}{l}\text { Wistar rats/tMCAO/ } \\
60 \mathrm{~min} / 24 \mathrm{~h}\end{array}$ & $\begin{array}{l}\mathrm{GCSF} / 15 \mathrm{mg} / \mathrm{kg} / 1 \mathrm{~h} \text { after } \\
\text { reperfusion/s.c. versus vehicle } \\
\text { + Hypothermia/30 min/onset of } \\
\text { reperfusion/versus vehicle }\end{array}$ & $\downarrow$ & $\begin{array}{l}\uparrow \text { Neurological deficit score } \\
\downarrow \text { Mortality } \\
\uparrow \uparrow \text { Neurological deficit score }\end{array}$ & $\begin{array}{l}\text { Combined treatment of GCSF with } \\
\text { hypothermia provided greater efficacy } \\
\text { in reducing infarct volume and } \\
\text { improving the somatosensory and } \\
\text { motor function of rats with cerebral I/R } \\
\text { injury in comparison to the single } \\
\text { treatment of GCSF }\end{array}$ & [37] \\
\hline $\begin{array}{l}\mathrm{SD} \text { rats } / \mathrm{MCAO} / \\
90 \mathrm{~min} / 24 \mathrm{~h}\end{array}$ & $\begin{array}{l}\mathrm{GCSF} / 50 \mu \mathrm{g} / \mathrm{kg} / \mathrm{d} 1 \mathrm{~d} \text { after } \\
\text { cerebral ischemia for } 5 \mathrm{~d} / \mathrm{s.c} . \\
\text { versus vehicle }\end{array}$ & $\downarrow(7-28 \mathrm{~d}$ & $\begin{array}{l}\uparrow \text { Body asymmetry test (14- } \\
28 \mathrm{~d}) \\
\uparrow \text { Vertical activity }(21-28 \mathrm{~d}) \\
\uparrow \text { Vertical movement time } \\
(14-21 \mathrm{~d})\end{array}$ & $\begin{array}{l}\text { GCSF treatment reduced infarct } \\
\text { volume and improved body asymmetry } \\
\text { and locomotor activity, neural } \\
\text { plasticity, and vascularization in rats } \\
\text { with cerebral I/R injury }\end{array}$ & [41] \\
\hline $\begin{array}{l}\mathrm{CD} 36^{-/-} \text {mice } / \mathrm{WT} \\
\text { bone marrow/ } \\
\mathrm{tMCAO} / 35 \mathrm{~min} / 24 \\
\text { and } 72 \mathrm{~h}\end{array}$ & $\begin{array}{l}\mathrm{GCSF} / 1 \mu \mathrm{g} / 24 \mathrm{~h} \text { after } \mathrm{MCAO} / \\
\text { i.c.v. versus vehicle }\end{array}$ & $\uparrow$ & - & $\begin{array}{l}\text { GCSF/CSF3 administration increased } \\
\text { infarct volume in CD } 36^{-/-} \text {mice with } \\
\text { WT bone marrow with cerebral I/R } \\
\text { injury }\end{array}$ & {$[35]$} \\
\hline
\end{tabular}

CD36, multifunctional Class B scavenger receptor; GCSF, granulocyte colony stimulating factor; $\mathrm{I} / \mathrm{R}$, ischemia/reperfusion; $\mathrm{L}-\mathrm{NAME}, \mathrm{L}-\mathrm{N}^{\mathrm{G}}$-nitroarginine methyl ester; MCAO, middle cerebral artery occlusion; MLPT, modified limb placing test; mNSS, modified neurological severity score; NSS, neurological severity score; rhGCSF, human recombinant granulocyte stimulating factor; SD, Sprague Dawley; SHR, spontaneously hypertensive rats; tMCAO, transient middle cerebral artery occlusion; tPA, tissue plasminogen activator; WT, wild type; $\leftrightarrow$, no significant change.

3 days after ischemia. This discrepancy is potentially in relation to the peak period of post-infarction edema [40]. Collectively, these studies indicate that GCSF administration by either single or multiple dose, during or after ischemia and short - or long-acting form reduced neurological deficits and infarct volume following cerebral I/R injury. According to these data, while preclinical, it can be inferred that $50 \mu \mathrm{g} / \mathrm{kg}$ of GCSF given at a clinically relevant time (during ischemia or after reperfusion) is an auspicious therapeutic strategy exerting brain protective effects on the brain following cerebral I/R injury. All findings are summarized in Table 1.

\section{The Protective and Reparative Mechanisms of GCSF in the Brain following Cerebral I/R Injury}

The possible mechanism underlying the brain protective and repairing potential of GCSF in the brain following cerebral I/R injury could be related to a multitude of processes, which includes stem cell mobilization, antiapoptosis, neurogenesis, anti-inflammation, and angiogenesis. The possible mechanism of exogenous and endogenous GCSF in the brain following cerebral I/R injury is summarized in Figures 2 and 3.

\section{Stem Cell Mobilization}

GCSF administration mobilizes $\mathrm{CD} 34^{+}$hematopoietic stem cells from the bone marrow into the peripheral blood [38]. Additionally, GCSF is thought to mobilize endogenous $\mathrm{CD} 34^{+}$and promote their presence to the injury site in the rat brain to support plasticity and functional recovery of damaged tissue. The administration of GCSF significantly increased mobilized $\mathrm{CD} 34^{+}$cells, which migrated to the marginal zone of infarction following cerebral I/R injury at 7, 14, and 21 days [38]. Furthermore, a large proportion of stem cells mobilized by GCSF expressed CXCR4/R on their cell surface, and cerebral ischemia is known to evidently increase the ligand of CXCR4/R, stromal cell-derived factor-1 (SDF-1). This chemokine may also signal adhesion and migration of hematopoietic stem cells to ischemic tissue [35]. Therefore, in the same study, an increased expression of CXCR4 was observed in the ischemic region of GCSF-treated rats compared to the contralateral nonischemic side or control [35], suggesting the directional migration of $\mathrm{CD} 34^{+}$cells toward SDF-1. Fascinatingly, the neutralization of CXCR4/R was associated with only a slight decrease in infarct volume in rats following GCSF administration [35]. This further implies that the role of GCSF in stroke recovery is mediated through the binding of SDF-1 to CXCR4/R. 


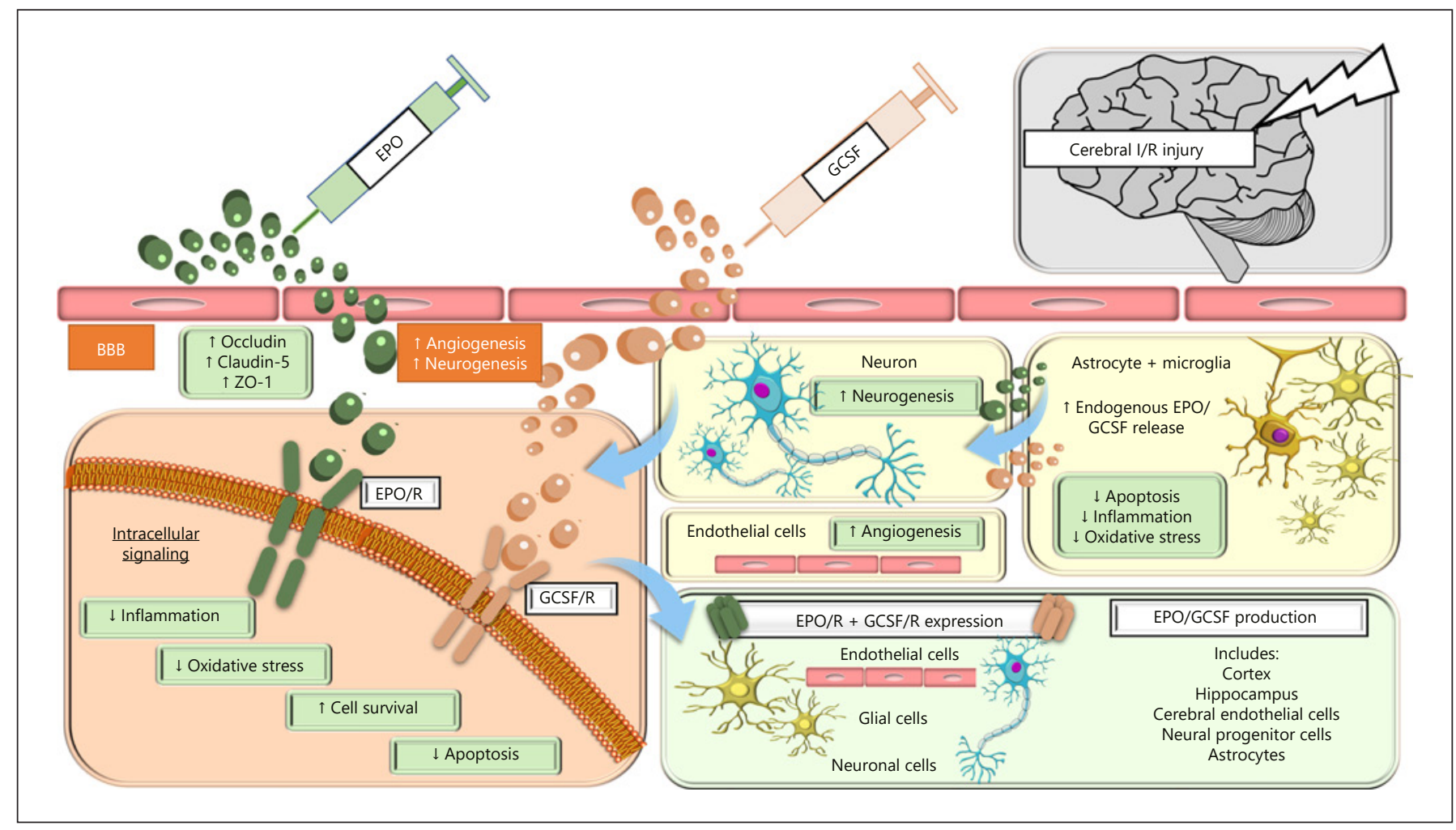

Fig. 2. The possible mechanism of exogenous and endogenous erythropoietin (EPO) and granulocyte colonystimulating factor (GCSF) in the brain following cerebral ischemia/reperfusion (I/R) injury is related to a multitude of processes, which include antiapoptosis, neurogenesis, anti-inflammation, and angiogenesis. Notably, GCSF, EPO, EPO/R, and GCSF/R are co-expressed in cerebral endothelial cells, neural progenitor cells, astrocytes, and by neurons in the hippocampus and the cortex.

Alternatively, the migration of bone marrow-derived monocytes decreased in chimeric mice subjected to transient middle cerebral artery occlusion (tMCAO) following GCSF treatment. This implies GCSF-induced brain protection does not involve bone marrow-derived cells [37]. Taken together, the existing body of literature is limited and contradictory findings cast uncertainty that the mobilization of stem cells is the sole or most significant mechanism of GCSF in the recovery following cerebral I/R injury. All findings are summarized in Table 2 .

\section{Antiapoptotic Effects}

Cell damage induced by prolonged cerebral I/R injury may lead to apoptosis, autophagy, necrosis, and necroptosis [22]. A growing body of literature recognizes GCSF exerts an antiapoptotic effect by Janus kinase 2 (JAK) signaling primarily through 3 independent antiapoptotic pathways: the signal transducer and activation of transcription (STAT) 3, the extracellular signal-regulated ki- nase (ERK), and phosphatidylinositol 3-kinase (PI3K)Akt pathway [22]. Neuronal apoptosis aside, another implication of the pathophysiology of cerebral I/R injury is glial cell death. The preservation of glial cells, particularly astrocytic metabolism and survival, is crucial to protect neurons against ischemic injury. GCSF treatment increased neuronal and glial survival by the activation of several antiapoptotic pathways [34]. According to several studies, a consensus has been reached regarding the significance of the JAK2/STAT3 signaling pathway enabling GCSF to regulate apoptosis-related protein expression, such as BCL-2, caspase-3, and BCL-2-associated X protein, in the ischemic area after I/R damage $[34,37]$. Komine-Kobayashi et al. [37] reported that bone marrowderived monocytes/macrophages may not be involved in GCSF-induced brain protection, but rather GCSF exerts brain protection through direct activation of antiapoptotic pathway, JAK/STAT3. Moreover, GCSF increased the expression of cellular inhibitor of apoptosis protein 2 (cIAP2) and thereby decreased activation of caspase 3 


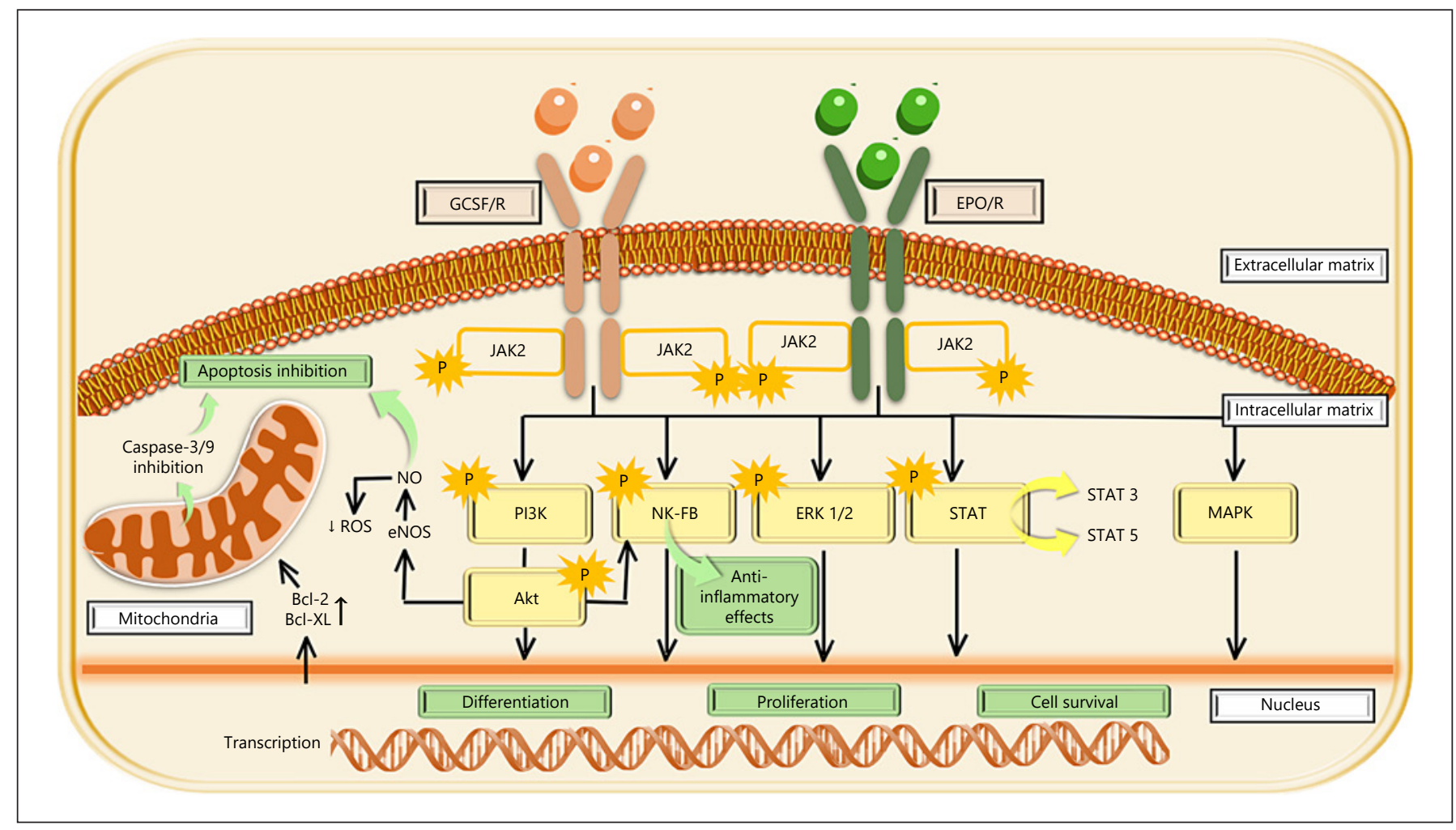

Fig. 3. The possible post-receptor signaling pathways involved in EPO/GCSF-mediated tissue protection are JAK/ STAT, MAPK, PI3K/Akt, ERK1/2, and NF- $\kappa$ B. EPO and GCSF confer neuroprotection by promoting cell viability by repressing apoptotic signals, exerting anti-inflammatory effects, and inducing cell proliferation and differentiation. EPO, erythropoietin; GCSF, granulocyte colony-stimulating factor; STAT, signal transducer and activation of transcription; MAPK, mitogen-activated protein kinase; PI3K, phosphatidylinositol 3-kinase; ERK, extracellular signal-regulated kinase; NF- $\mathrm{B}$, nuclear factor kappa B.

[34]. The antiapoptotic mechanism of cIAP2 is not well elucidated, but this result suggests GCSF mediated glial cell survival; however, an in vitro study would provide better insight regarding the presence of GCSF/R on astrocytes.

Furthermore, GCSF treatment may exert its antiapoptotic effects by regulating the activation of the JNK signaling pathway, which is associated with a classic downstream of apoptosis-related proteins [40]. The activity of $\mathrm{p}$-JNK and p-c-jun significantly decreased in the cerebral ischemia-reperfusion-damaged cortex and hippocampus in rats following GCSF administration. Therefore, this pathway is potentially liable for the neuronal protection following GCSF treatment [40]. Taken together, it is important to note that GCSF exerts antiapoptotic effects by triggering various signaling pathways and the precise mechanism remains obscure. All findings are summarized in Table 2.

\section{Neurogenesis}

New neurons are continuously generated in the adult brain in distinct brain regions, particularly in the subventricular zone and the dentate gyrus in the hippocampus [45]. Distinct populations of neuronal stem cells possessing multipotency and plasticity and a particularly high expression of GCSF reside in the mentioned brain regions. According to previous literature, GCSF induced receptor-mediated proliferation and differentiation of neural precursors $[22,39]$.

The capability of GCSF to enhance neurogenesis has been established as a single dose of GCSF treatment at the onset of reperfusion, led to increased numbers of NeuN/ $\mathrm{Brdu}^{+}$cells 7 days after initiating cerebral I/R injury. However, NeuN/Brdu ${ }^{+}$cells returned to levels corresponding to the vehicle-treated group at 28 days; therefore, GCSF enhances neurogenesis in the acute phase. Based on the data available, GCSF significantly contributes to the augmentation of neurogenesis and neuroblast 


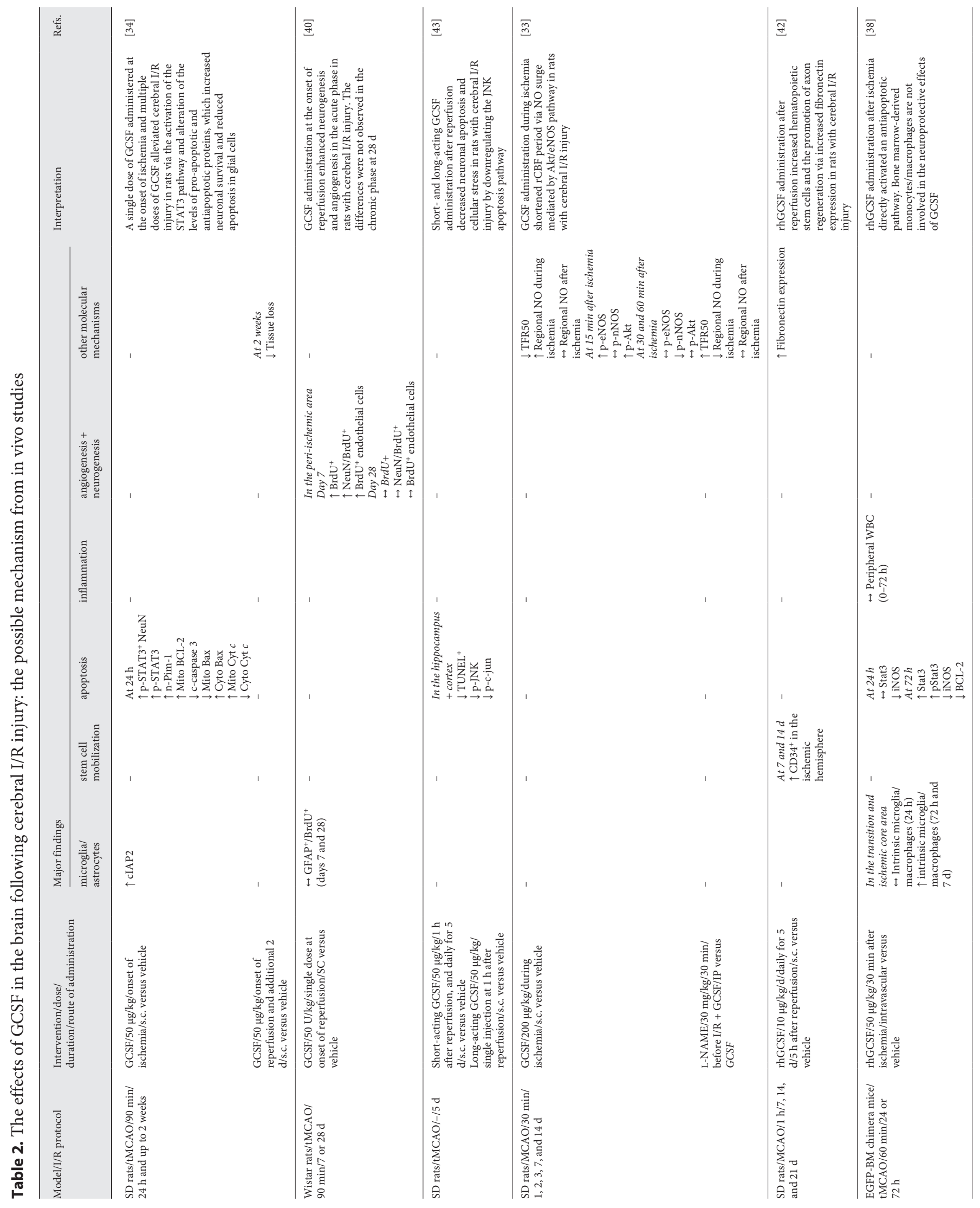




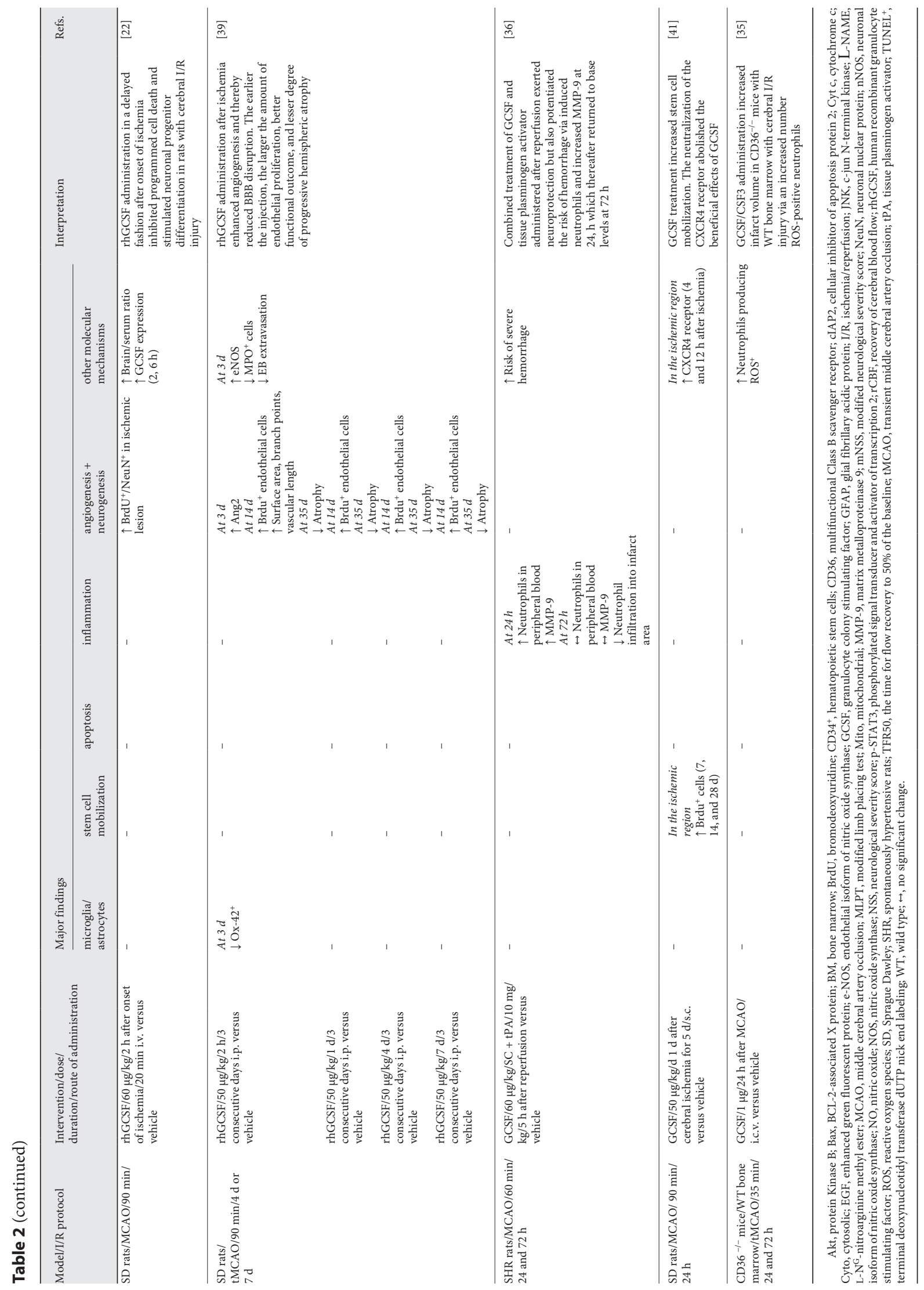


migration, with the activation of STAT3 and 5 and PI3K/ Akt signaling pathway and increase in vascular endothelial growth factor and its receptor and activation [22,39].

An intricate interplay among proliferation, differentiation, and selective survival underlies the production of differentiated cells from stem cells. A noteworthy in vivo study demonstrated the peripheral infusion of GCSF increased the recruitment of progenitor cells from the lateral ventricular wall into the ischemic area of the rat neocortex [22]. The most prominent effect of GCSF on neurogenesis was seen in the dentate gyrus, where the number of newly generated neurons was increased in the ischemic and nonischemic condition [22]. Accordingly, GCSF may promote structural repair and could be considered a novel therapeutic strategy for the treatment of stroke [22] Although the predominant role of GCSF in the survival and differentiation of progenitor cells in the postischemic brain is promising, further studies are warranted to determine the molecular basis. All findings are summarized in Table 2.

\section{Anti-Inflammation}

Cerebral I/R injury triggers inflammatory cascades in the brain parenchyma, which intensifies tissue damage and plays a causative role in reperfusion injury. GCSF is an agent with brain protective and repairing potential that can curtail neuroinflammation and prove to be an effective therapeutic agent. The brain responds to cerebral I/R injury through an acute and prolonged inflammatory process, characterized by the aberrant activation of glial cells, particularly microglia and astrocytes; production of pro-inflammatory mediators; the infiltration of leukocytes; and the deterioration of the BBB [46].

Microglia cells, the resident macrophages, are activated rapidly following brain injury and produce a plethora of pro-inflammatory mediators including IL-B and TNF- $\alpha$, which exacerbate tissue damage [47]. GCSF treatment may have provided brain protection by an increased expression of intrinsic microglia/macrophages at the ischemic penumbra in chimeric mice known to express enhanced green fluorescent protein [37]. Additionally, astrocytes, the most abundant housekeeping glial cells in the brain, play a crucial role in conferring resistance to ischemic damage. Wellknown astrocyte functions include maintenance of the $\mathrm{BBB}$, trophic support of neurons, and regulation of local inflammatory responses [48]. Damage to the supportive roles of astrocytes constitutes a threat to neuronal survival. GCSF treatment increased neuronal and glial survival shown by an increased expression of
cIAP2, and this effect of GCSF contributed to remarkable tissue preservation and behavioral recovery following cerebral I/R injury [34].

Furthermore, GCSF treatment following cerebral I/R injury exerts brain protection through the activation of Akt/endothelial isoform of nitric oxidesynthase (eNOS) pathway, resulting in advantageous $\mathrm{NO}$ release and the improvement of cerebral blood flow in the ischemic brain [33]. Previously, NO release was considered neurotoxic; however, NO generated by eNOS is considered to be a neuroprotective agent [33]. In the early stage of brain ischemia, the early activation of eNOS and neuronal isoform of nitric oxide synthase (nNOS) facilitated a sharp rise in $\mathrm{NO}$ and consequently the early recovery of $\mathrm{rCBF}$, reduced infarct volume, and neurological deficits [33]. GCSF effects on NO production were immediate due to eNOS and nNOS activity, whereas the catalytic activity of iNOS is detected only $12 \mathrm{~h}$ after cerebral ischemia and peaks after $48 \mathrm{~h}$ [33]. However, with regard to nitrosative stress, the rapid reaction of $\mathrm{NO}$ with superoxide $\left(\mathrm{O}^{--}\right)$ forms peroxynitrite $\left(\mathrm{ONOO}^{-}\right)$. On that note, GCSF treatment inhibited iNOS and subsequently inhibited peroxynitrite production, which provided protection against cerebral ischemia [37].

Following cerebral I/R injury in the subacute phase, the infiltration of leukocytes releases cytokines and chemokines and induces excessive production of ROS and activation of MMP (mainly MMP-9), which amplifies the brain inflammatory responses [47]. Thereafter, extensive activation of resident cells and infiltration of leukocytes lead to BBB disruption, brain edema, and neuronal death [47]. However, the time course of inflammatory events is of significance, as MMP-9 is detrimental in early ischemic brain damage but has shown to promote brain regeneration and neurovascular remodeling in the later repair phase [47].

Indeed, reduced infiltration of neutrophils and reduced BBB disruption are observed after treatment of GCSF following cerebral I/R injury [36, 41, 43]. GCSF administration following cerebral I/R injury significantly reduced infiltration of neutrophils [41]. Moreover, leukocytosis and MMP-9 were restricted to the vessel compartment and did not exacerbate the brain lesion [41]. Unfortunately, in this study, the hemorrhagic risk was increased by GCSF treatment in combination with tPA following cerebral I/R; this consequence is potentially due to the vascular alteration mediated by the MMP-9 release from peripheral neutrophils [41]. Nevertheless, the increment of inflammatory infiltration appears to be no issue in GCSF treatment for stroke. 
Interestingly, CD36, is an innate immunity receptor involved in the initiation of postischemic inflammation and regulator of neutrophil cytotoxicity. Endothelial CD36 initiated the mentioned detrimental effects by upregulating the neutrophil activator GCSF in cerebral endothelial cells [43]. Therefore, Garcia-Bonilla and colleagues ultimately unveil the "dark side" of GCSF in ischemic brain injury by demonstrating its role in the post-ischemic ROS production by neutrophils, a CD36dependent effect. However, further investigation regarding the CD36-CSF3 axis is needed. All findings are summarized in Table 2.

\section{Angiogenesis}

Angiogenesis following cerebral I/R injury is a process that causes vessels to arise from preexisting vessels [49]. The induction of angiogenesis, primarily in the ischemic boundary zone, can be considered a natural defense mechanism, as it enhances the oxygen and nutrient supply to the affected tissue [50]. GCSF enhances angiogenesis without disrupting the BBB [36]. The growth of new blood vessels enables highly neurorestorative processes and thereby potentially improving long-term recovery. GCSF administration has emerged as a therapeutic option to enhance angiogenesis following cerebral $\mathrm{I} / \mathrm{R}$ injury. GCSF treatment following cerebral I/R injury increased endothelial proliferation, vascular area, vascular branch points, and vascular length in the ischemic hemisphere [36]. Interestingly, the delayed administration of GCSF up to 7 days remained effective, but earlier treatment resulted in a larger amount of endothelial proliferation and better functional outcome [36]. However, further studies are required to validate the functional effect of angiogenesis. In addition, in a study conducted by Sehara et al. [39], an increase in bromodeoxyuridine-positive endothelial cells was observed, further emphasizing the role of GCSF treatment in promoting angiogenesis following tMCAO. All in all, the existing body of research suggests angiogenesis is one of the fundamental processes through which GCSF treatment reduces ischemic damage and promotes long-term functional recovery. All findings are summarized in Table 2.

\section{The Effects of EPO on Neurological Function and Infarct Volume following Cerebral I/R Injury}

Cerebral I/R injury leads to several calamitous effects, such as debilitating motor impairments, exacerbated functional outcomes, and the growth of large infarcts in the brain. EPO administration before ischemia [51-55], at the onset of reperfusion [56-62], and several hours after reperfusion $[63,64]$ as a single- or multiple-dose regimen $[57,63,65]$ exerted brain protection in rats with cerebral I/R injury at doses varying between 1,000 and 5,952 $\mathrm{IU} / \mathrm{kg}$. In a similar manner, variants of EPO, such as MK$\mathrm{X}$, asialo-erythropoietin (AEPO) and nonerythropoietic mutant EPO (MEPO), which are conceptually devoid of side effects, provided similar efficacy in reducing infarct volume and attenuating neurological deficits $[58,62,66]$. However, a growing body of literature addresses the indisputable brain protective effects exerted by EPO variants without hematopoietic complications and thereby ignites optimism for a robust and effective poststroke therapy. Moreover, several studies demonstrated EPO administration at the dose $5,000 \mathrm{IU} / \mathrm{kg}$ before ischemia $[53,54]$, at the onset of reperfusion [61], and several hours after reperfusion [64], effectively reduced infarct volume and attenuated neurological deficits in rats with cerebral I/R injury. Nonetheless, EPO exerted a lesser impact or a deleterious effect with regard to brain protection against cerebral I/R injury in rats $[54,55,57,62,65]$.

Debate continues regarding the most effective regimen of EPO to ameliorate neurological function and reduce infarct volume. Contradictory to previous bolstering findings, pretreatment with a single and low dose of human recombinant EPO (rhEPO) (1,000 IU/kg) $10 \mathrm{~min}$ before MCAO in rats exhibited a lesser impact on infarct volume but ameliorated neurological function at $24 \mathrm{~h}$ compared to the vehicle-treated group [38]. This contradictory result may be in relation to the early time point of measurement, whereas a later time point could have provided a better insight. Moreover, some of the available literature on EPO addresses the efficacy of single- and multiple-dose regimens. A multiple-dose regimen of lower doses of EPO (1,000 IU/kg) provided better efficacy in reducing neurological deficits than a single dose of EPO $(5,000 \mathrm{IU} / \mathrm{kg})$ [57]. Unfortunately, this study did not observe which regimen results in the best long-term outcome. In contrast, a 2 dose-regimen of EPO $(2,500 \mathrm{IU} / \mathrm{kg})$ alone after MCAO failed to reduce ischemic lesion volume. Interference of EPO with other therapeutic agents, no doubt, must be addressed; therefore, in the same study, EPO was administered with IPA and failed to reduce infarct volume. Moreover, the underlying reason involves a hitherto unknown interaction of tPA with EPO as all beneficial effects were abolished [65].

The search for an effective agent that improves neurological recovery in combination with rtPA continues. In multiple studies, the ceiling effect caused by combined 
rtPA treatment meant combined drug treatment did not always result in synergy. Several agents have failed in stroke; this could be due to measuring the effectiveness of rtPA + drug compared to rtPA alone or the thrombolytic agent could be taking up the time window of the neuroprotective agent [67]. Ultimately, rtPA may reestablish blood flow in the penumbra region, and therefore, the benefit that EPO could provide is diluted, demonstrating the difficulty of improving the outcome on top of the effect of rtPA, caused by a ceiling effect of thrombolysis.

Recent studies have demonstrated systemic subcutaneous or intraperitoneal administration of EPO reduced neurological deficits in doses ranging 1,000-5,000 IU/kg at short- and long-term observation following cerebral I/R injury [52-55, 61, 62, 64, 66]. Unfortunately, higher doses of EPO were correlated with severe systemic side effects, for instance, red cell aplasia, hypertension, and thrombosis; therefore, a growing body of literature addresses EPO variants. A multiple-dose regimen of EPO and MEPO over 11 days administered at the onset of reperfusion similarly attenuated neurological deficits in the early periods of ischemic brain injury compared to the vehicle group. One unanticipated finding was that EPO, unlike MEPO, failed to reduce infarct volume. Therefore, nonerythropoietic MEPO can be considered a promising agent to complete the quest for an EPO derivative, which lacks the EPO activity but retains the brain protective and reparative properties to combat ischemic brain injury [66]. In a similar manner, a single dose of MK-X, a novel EPO-derived short peptide, efficiently reduced infarct volume following cerebral I/R injury; however, EPO failed to diminish ischemic lesion volume. This rather contradictory result may be due to $\mathrm{MK}$-X better penetrating the $\mathrm{BBB}$ compared to EPO [62]. Additionally, AEPO, a metabolite of EPO, administered with liposomal drug delivery system technology retained the capability to ameliorate motor activity and reduce infarct volume [58] without initiating notable erythropoiesis, coagulation, or thrombosis.

Moreover, researchers embark on the quest to find the lowest most effective dose of any pharmaceutical drug, and the route of administration, no doubt, influences the dose range in most cases. To date, there are a diverse array of administration routes, such as systemic (intraperitoneal or intra-arterial or subcutaneous), intravenous, and intracerebroventricular injections, which possess their downsides, such as undesirable systemic side effects to other tissues or brain damage and infections [63]. On that note, opting for a different route of EPO administration, such as intranasal administration or the administra- tion of EPO encapsulated in microbubbles (MBs), and with focused ultrasound (FUS) sonication diminished the systemic side effects, attenuated neurological deficits, and effectively reduced infarct volume $[63,68]$. Moreover, EPO administration with FUS and MBs, which opens the $\mathrm{BBB}$ to boost vascular permeability, lengthened the therapeutic window as brain protective effects were observed even at $5 \mathrm{~h}$ after cerebral I/R [64]. EPO possesses a limited therapeutic time window, the best application time is up to $3 \mathrm{~h}$ after ischemia with a leaky BBB [64].

Extremely high doses of EPO have been used for brain protection in I/R brain injury to deliver sufficient amounts of EPO across the BBB; however, detrimental side effects were observed afterward. Therefore, in one study, heparin-binding hemagglutinin adhesion c (HBHAc), an intracellular delivery peptide for macromolecules, was investigated as an EPO carrier across the BBB [69]. EPOHBHAc exhibited significantly higher cellular internalization in dose- and time-dependent manners and better transcytosis ability compared to EPO [69]. The calculated cerebral infarction area of rats treated with EPO-HBHAc was significantly reduced compared to that of rats treated with EPO. EPO amount in both CSF and damaged cortex from the EPO-HBHAc group was 4.0and 3.0-fold higher than that in the EPO group, respectively [69]. Thus, HBHAc would be a favorable tool for EPO brain delivery and would further extend the clinical applications of EPO in brain protection.

EPO has a relatively short half-life in the body; therefore, in one study, EPO was modified by PEGylation to create P-EPO. This form of EPO possesses long-term stabilization and half-life [70]. Administration of P-EPO $(5,000 \mathrm{IU} / \mathrm{kg})$ via intravenous injection in mice following $\mathrm{MCAO}$ exerted neuroprotective effects on cerebral ischemia damage through antioxidant and anti-inflammatory properties by inhibiting nuclear factor kappa $\mathrm{B}$ activation [70]. P-EPO was more effective than EPO (5,000 IU/ $\mathrm{kg})$ and similar to a tPA $(10 \mathrm{mg} / \mathrm{kg})$ [70].

In view of all that has been mentioned so far, one may suppose that the administration of a multiple- or singledose regimen of EPO before ischemia, at the onset of reperfusion, and several hours after reperfusion, for the most part, attenuated neurological deficits and effectively reduced infarct volume. However, a note of caution is due here, as the aforementioned cerebral I/R models subtly differ in ischemic duration.

Moreover, while pretreatment with EPO in the rat model of cerebral I/R injury highlights contradictory findings and sheds light on the protective ability of EPO, it does not directly benefit clinical development for 


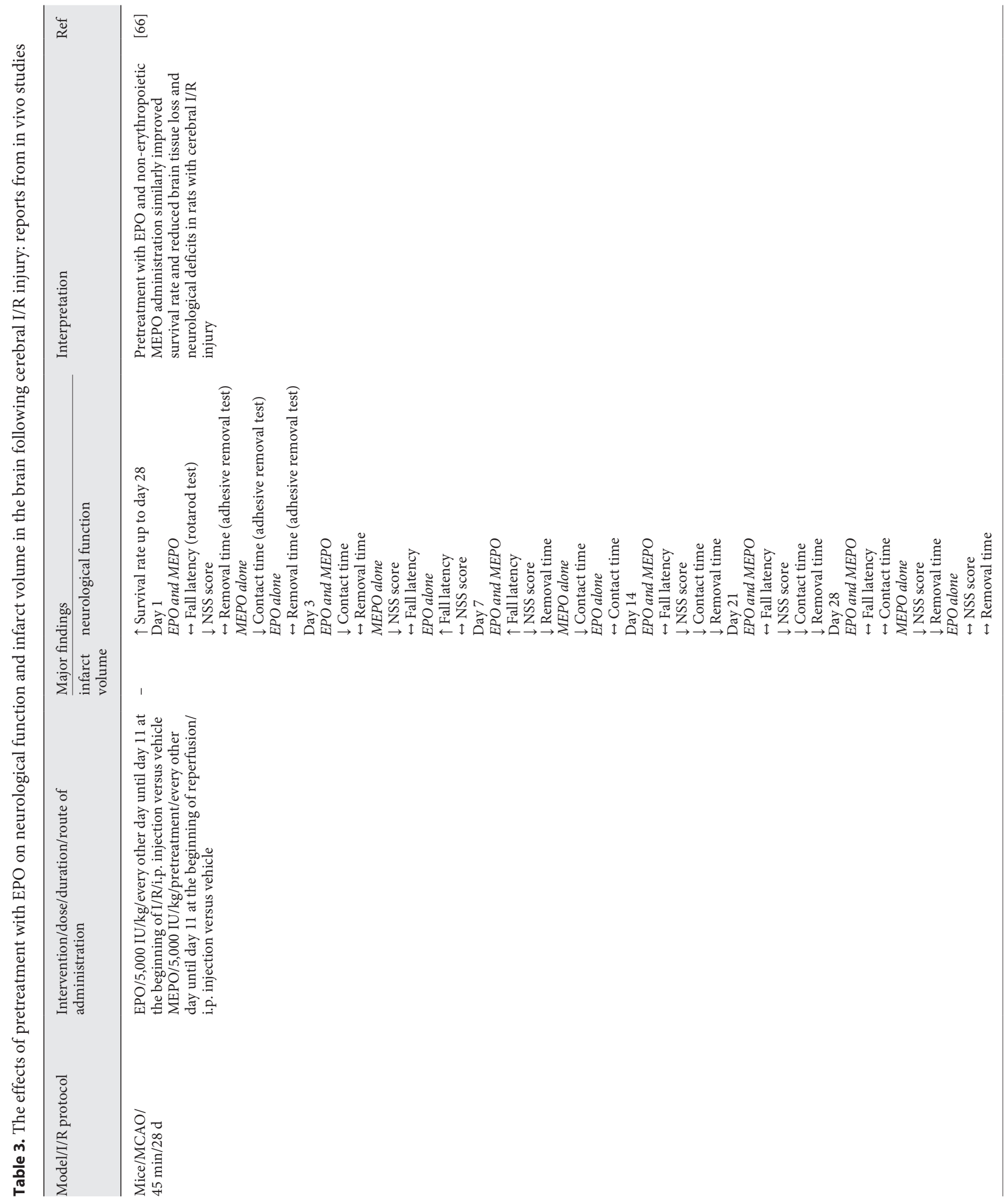




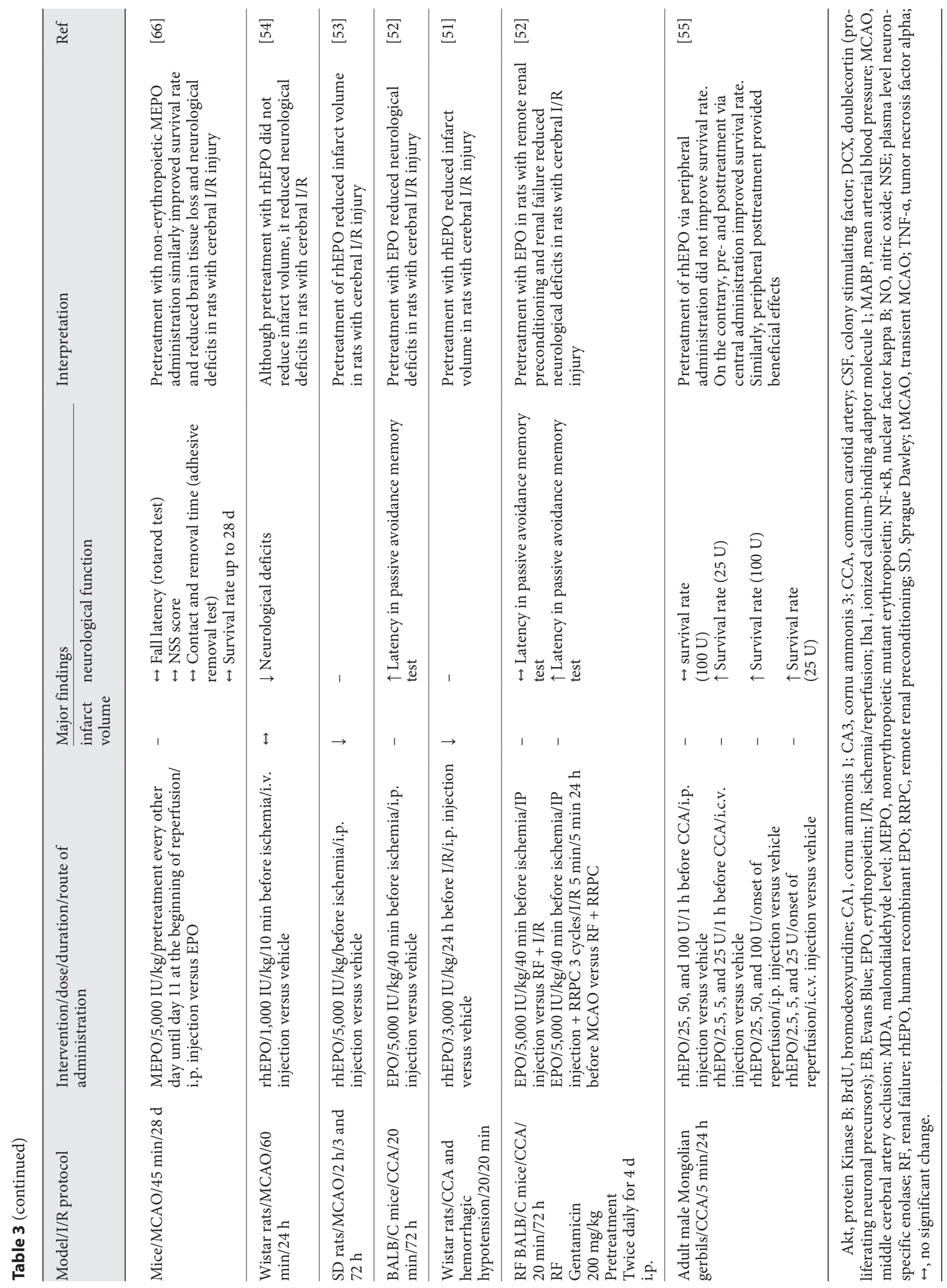


strokes. However, experimental pretreatment studies elucidated what may occur in stroke patients treated with EPO for preexisting medical conditions, such as kidney disease or anemia. All in all, according to the mentioned data, while preclinical, it can be inferred that 5,000 IU/kg of EPO given at a clinically relevant time (at the onset/ after reperfusion) is an auspicious therapeutic strategy exerting brain protective effects on the brain following cerebral I/R injury. However, there is abundant room for progress in clinical trials with regard to EPO variants, which have emerged as robust and effective poststroke agents in preclinical data. All findings are summarized in Tables 3 and 4.

\section{The Protective and Reparative Mechanisms of EPO in the Brain following Cerebral I/R Injury}

The possible mechanism underlying the brain protective and reparative potential of EPO in the brain following cerebral I/R injury could be related to a multitude of processes, which includes antiapoptosis, neurogenesis, anti-inflammation, and angiogenesis. The possible mechanism of exogenous and endogenous EPO in the brain following cerebral I/R injury is summarized in Figures 2 and 3 .

\section{Antiapoptosis}

EPO confers brain protection by promoting cell viability and repressing apoptotic signals. Similar to GCSF, the 3 well-known post-receptor signaling pathways involved in EPO-mediated tissue protection, JAK/STAT, mitogenactivated protein kinase (MAPK), and PI3K/Akt, have been conferred by both in vivo and in vitro studies. The ability of EPO to prevent apoptotic injury is reliant on inducing autophosphorylation of JAK 2, which subsequently phosphorylates and thus activates secondary signaling molecules, signal transducer, and activator STAT5, leading to the downstream transcription activation of BCL-2 [57, 62, 71]. Accumulating evidence from several studies show that EPO regulates apoptosis by inducing antiapoptotic molecules, BCL-2, or decreasing pro-apoptotic molecules, such as BCL-2-associated X protein. Additionally, associated with the JAK2-STAT signaling pathway are multiple secondary signaling pathways, including MAPK, ERK1/2, and PI3K pathways [62]. The phosphorylation and activation of STAT5 have been implicated in the upregulation of antiapoptotic genes as well as nuclear factor kappa $\mathrm{B}$, an inflammatory mediator [57].
Additionally, in vivo and in vitro experiments investigated the potential of EPO-based short peptide derivative, MK-X, and further illustrated the mechanistic concepts of EPO, similar to that of MK-X. In the in vitro study, MK-X and EPO similarly inhibited caspase-dependent and caspase-independent cell death under glutamate-induced toxicity. There was a profound reduction in caspase-3 cleavage, final executor of caspase-dependent cell death, and apoptosis-inducible factor, initiator of caspase-dependent cell death [62]. Although MK-X and EPO exhibit somewhat differential kinetics, both displayed increased phosphorylation of STAT5, Akt, and ERK1/2. The upregulation of Akt and MEK activity during injury has demonstrated to be crucial for EPO-mediated protection, as inhibition diminished the effects of Akt and ERK1/2 pathways [62]. More importantly, the BCL-2 expression was inhibited by blocking PI3K, but not by blocking MEK. It can thus be suggested that EPO and MK-X exert brain protection mainly through both ERK and Akt, however, in different manners [62]. According to these data, we can infer that EPO exerts brain protection partly through its antiapoptotic properties. Findings for in vivo studies are summarized in Tables 5 and 6 . Findings for in vitro studies are summarized in Table 7.

\section{Neurogenesis}

Similar to GCSF, EPO plays a pivotal role in modulating neurogenesis following cerebral I/R injury $[56,57$, 66]. This versatile growth factor assists the proliferation and development of neural progenitor stem cells. EPOmediated activation of the aforementioned ERK and PI3K/Akt pathways has the additional role of promoting neural progenitor cell migration [57].

As a neutrophil-cytokine, EPO-mediated increase of neurogenesis has widely been reported. In vivo and in vitro findings further corroborate the role of EPO and MEPO in neurogenesis: a substantial increase in $\mathrm{DCX}^{+} /$ $\mathrm{BrdU}^{+}$cells in regions of peri-infarction 14 days after MCAO in mice. Doublecortin (DCX, a marker for neuronal precursors) and NeuN (a marker for mature neurons) were used to indicate endogenous neurogenesis [66]. Markedly, $\mathrm{Ki} 67^{+}$, a biomarker for cell proliferation, demonstrated EPO enhanced neurogenesis and angiogenesis but inhibited excessive gliogenesis. In this study, neurogenesis occurs in the ischemic boundary zone, not in the subventricular zone and subgranular zone [72]. This rather contradictory result is potentially related to the detection time. Neurogenesis and angiogenesis are not entirely independent pathways, but rather interrelat- 


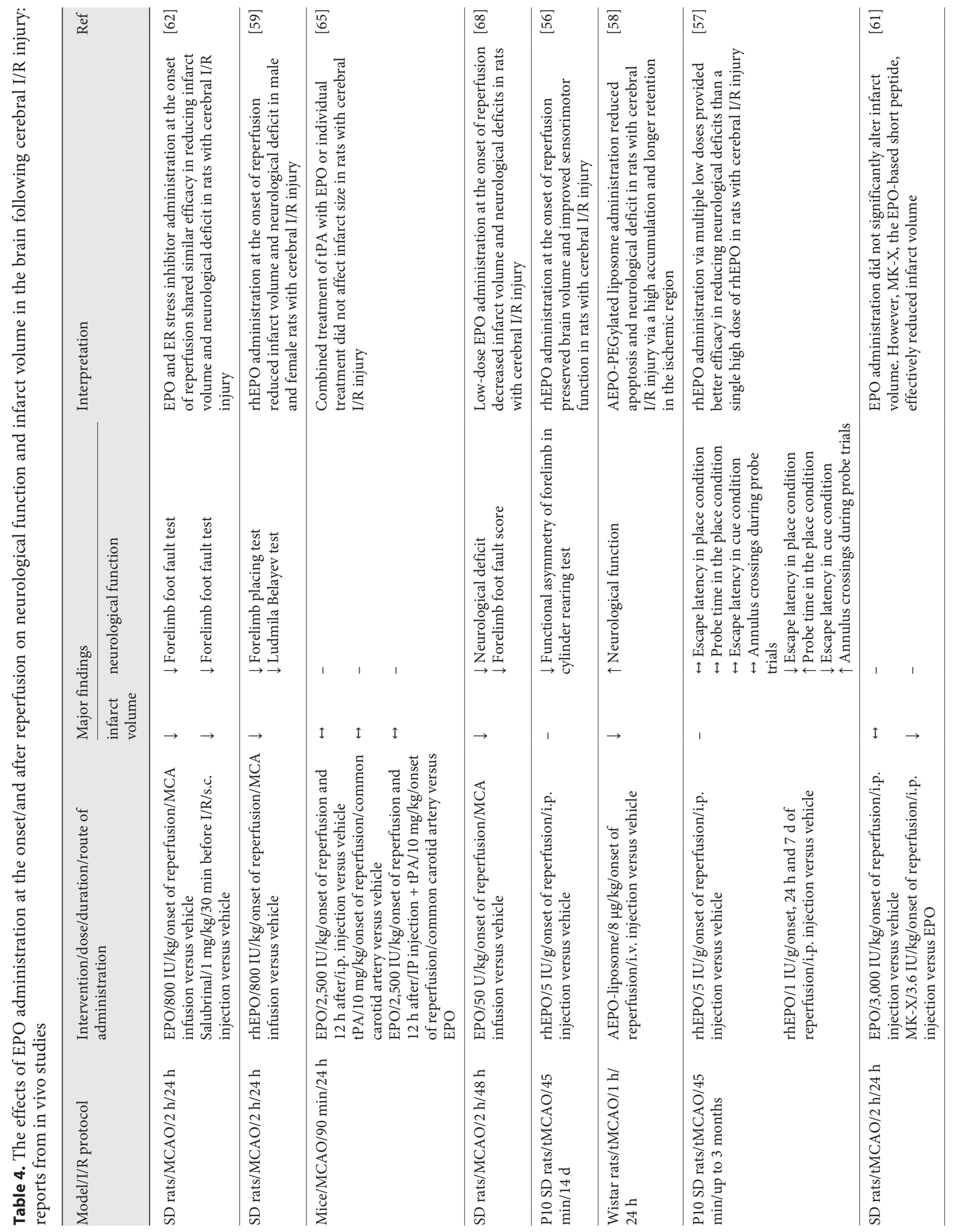




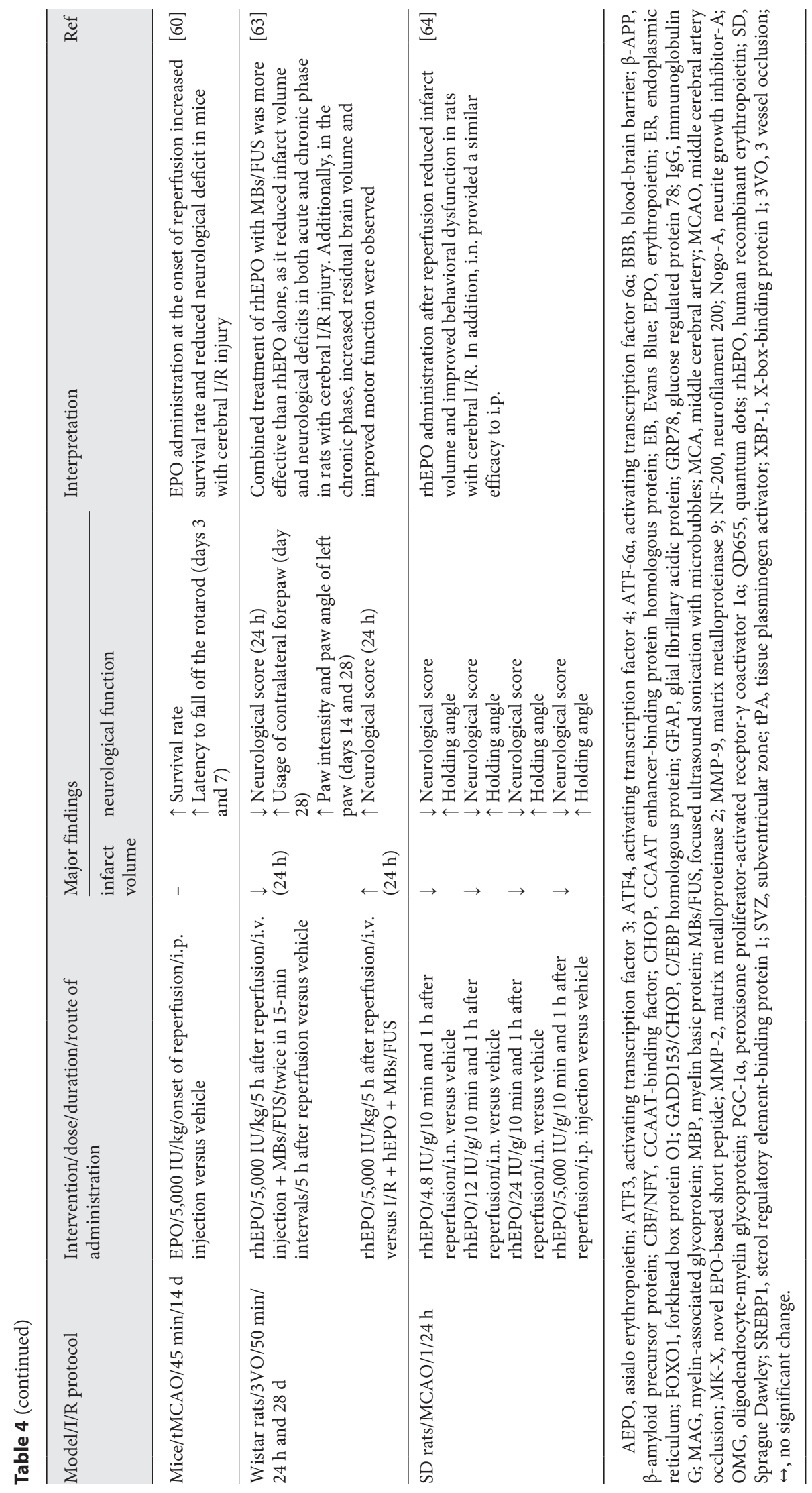




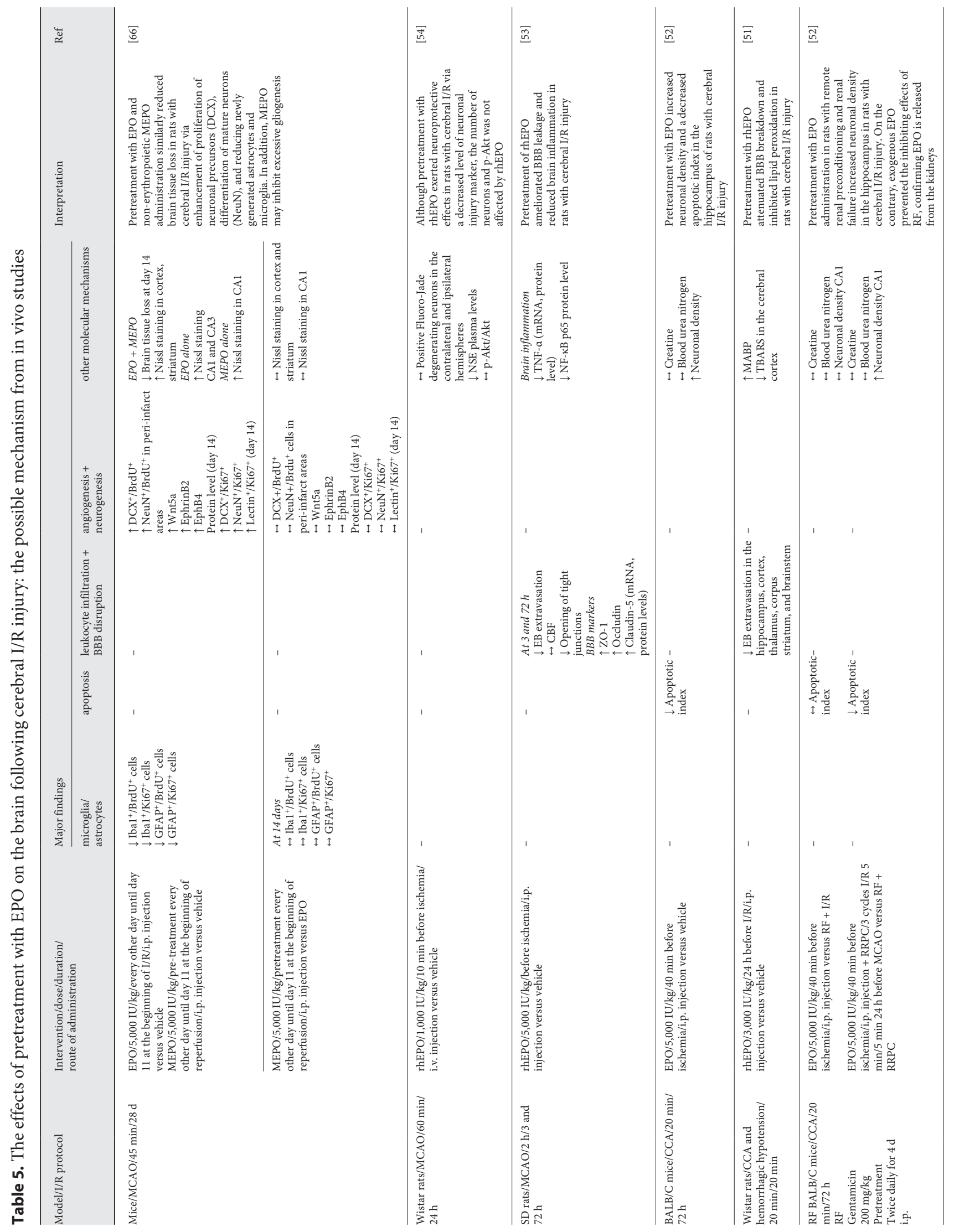




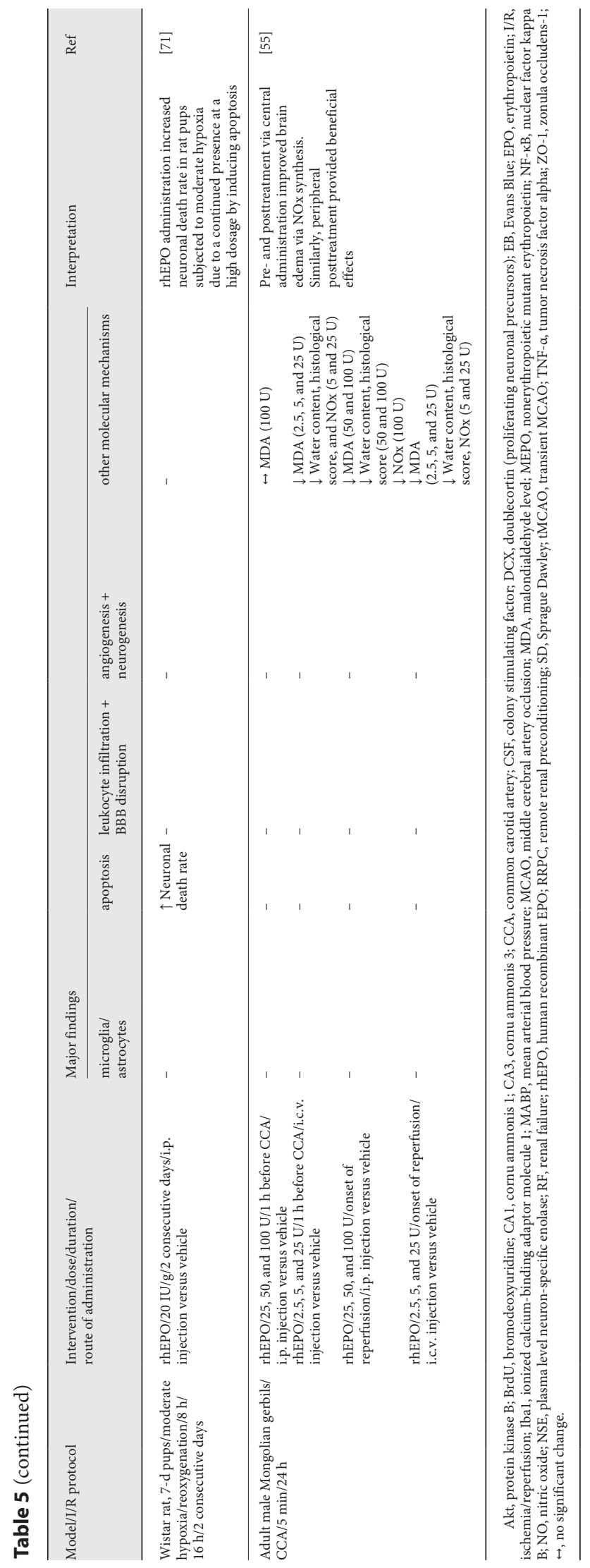

ed [72]. Moreover, EPO and MEPO activated Wnt signaling pathway, necessary for the differentiation of progenitors to neurons, and EphB4/EphrinB2 signaling pathways, important in angiogenesis and which thereafter provides a basis for neurogenesis [66].

Additionally, the capability of EPO to promote neurogenesis in the acute phase following cerebral I/R injury has been demonstrated; however, a single dose of EPO has little to no effect on later neurogenesis and proliferation; therefore, the optimal dosing regimen to maximize long term outcome needs to be elucidated [57]. Thus far, previous findings indicate that EPO is involved in neurogenesis under physiological and pathological conditions. Findings for in vivo studies are summarized in Tables 5 and 6 . Findings for in vitro studies are summarized in Table 7.

\section{Oxidative and Nitrosative Stress}

Oxidative stress and nitrosative stress occur due to the manifestation of free radicals, mainly ROS/reactive nitrogen species (RNS), which thereby overwhelms the endogenous scavenging capacity of antioxidant defense systems. During ischemia, the failure of oxidative phosphorylation and ATP synthesis adversely affects $\mathrm{Na}^{+} / \mathrm{K}^{+}$ ATPase pump and thereby results in NMDAR-mediated excitotoxicity, excessive $\mathrm{Ca}^{2+}$ influx, mitochondrial dysfunction, and nNOS activation [73]. EPO-mediated protection is robust and involves preventing toxicity from multiple sources.

The ability of EPO to ameliorate mitochondrial damage under glutamate-induced excitotoxicity by inhibiting calcium overload and oxidative stress is corroborated by an in vitro study [62]. In this study, EPO and MK-X, an EPO-derived short peptide, similarly reduced ROS generation; however, EPO-mediated brain protection under oxidative stress was abolished by inhibiting the secondary signaling pathways, ERK1/2 and Akt. The PI3K/Akt signaling pathway modulates $\mathrm{Ca}^{2+}$, whereas the MAPK/ERK pathway endorses functional recovery of mitochondria from excitotoxicity [62]. All in all, EPO and potentially a few EPO-derived analogs have antiapoptotic properties by inducing the synthesis of antioxidants and have an anti-excitotoxic effect under oxidative stress. Findings for in vivo studies are summarized in Tables 5 and 6 . Findings for in vitro studies are summarized in Table 7.

\section{Leukocyte Infiltration and BBB Disruption}

The consequences of leukocyte infiltration and subsequent $\mathrm{BBB}$ disruption following cerebral I/R have been previously discussed. An extensive amount of literature 


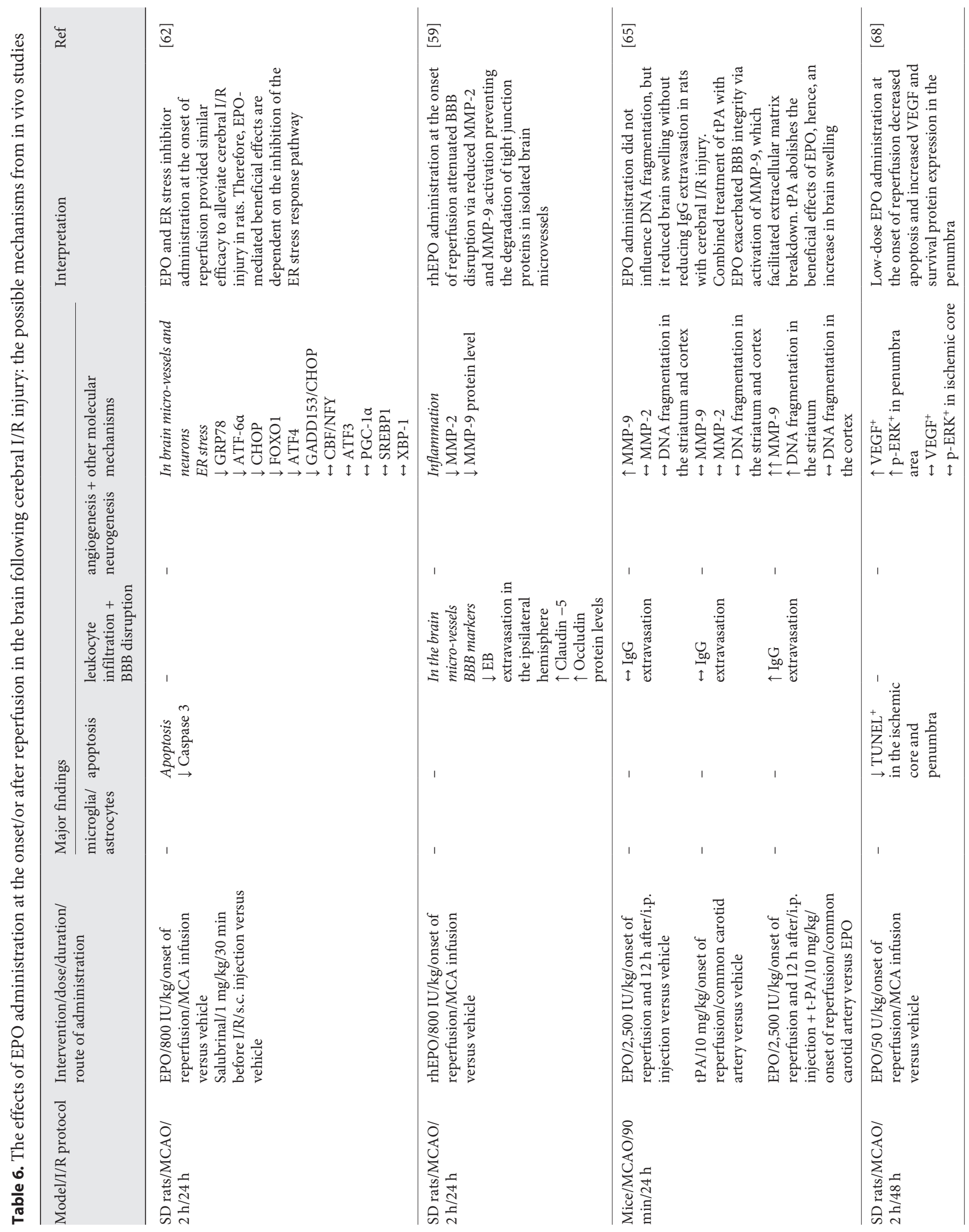




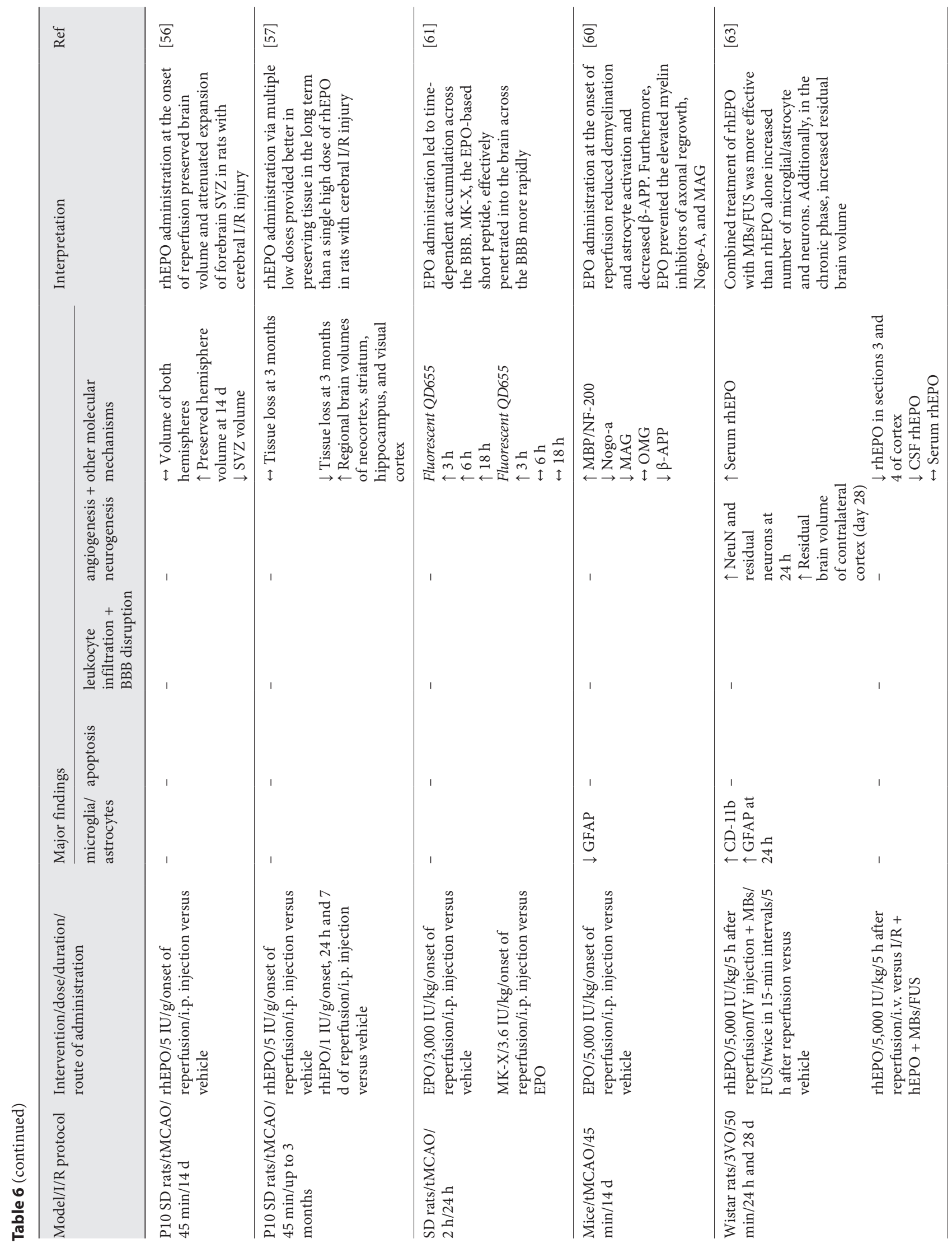



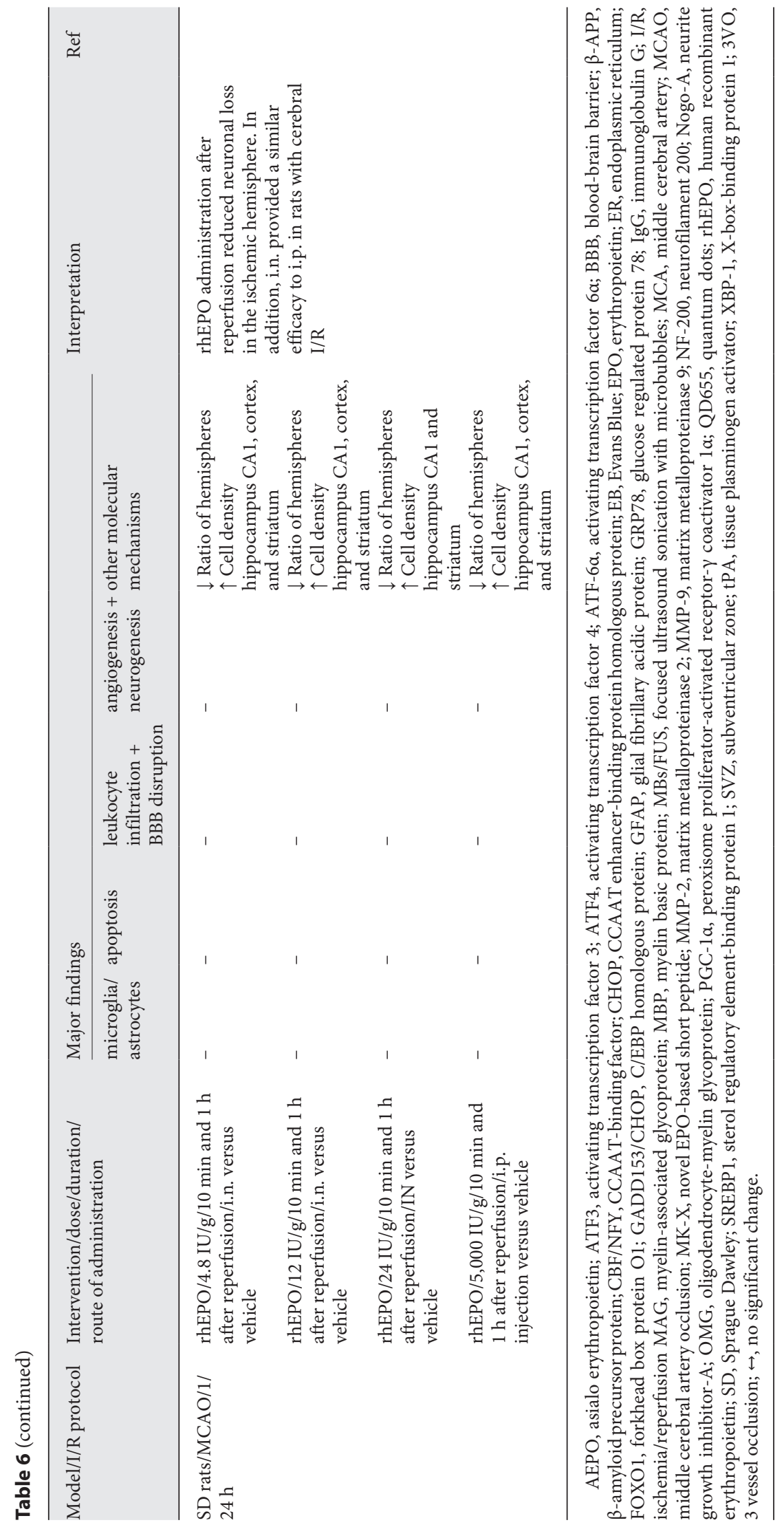
has addressed the role of exogenous EPO in preventing $\mathrm{I} / \mathrm{R}$ induced leukocyte infiltration and BBB breakdown. $\mathrm{BBB}$ integrity is crucial to the homeostasis of the brain microenvironment, for the most part, through complex tight junctions between endothelial cells, which limit the movement of hydrophilic molecules [52]. Several studies have investigated the effects of EPO on $\mathrm{BBB}$ integrity, commonly by using Evans Blue (EB), a biomarker of $\mathrm{BBB}$ permeability.

Related findings from an in vivo study demonstrated the systemic administration of EPO $24 \mathrm{~h}$ before cerebral ischemia prevented $\mathrm{BBB}$ breakdown in the hippocampus, cortex, corpus striatum, midbrain, brain stem, and thalamus, as shown by EB extravasation [52]. Similarly, another in vivo study provided evidence that the administration of EPO through middle cerebral artery infusion at the beginning of reperfusion inhibited MMP-mediated $\mathrm{BBB}$ disruption. In this study, the $\mathrm{EB}$ extravasation in the ipsilateral hemisphere was decreased and the I/R-elicited upregulation of MMP-9 and MMP-2 was attenuated, as indicated by preventing the degradation of tight junction proteins (claudin- 5 and occludin) in isolated brain microvessels [59]. In a similar manner, Liu et al. [53] further validate that EPO treatment upregulated the expressions of zonula occludens-1, occludin, and claudin-5 involved in the modulation of tight junction integrity and thereby enabled EPO-mediated amelioration of BBB leakage as shown by a decrease in EB extravasation. Additionally, $\mathrm{BBB}$ permeability was increased in a biphasic manner at 3 and $72 \mathrm{~h}$ of reperfusion in cerebral I/R rats [53].

On the contrary, co-treatment of EPO with tPA exacerbates $\mathrm{BBB}$ permeability, closely accompanied by an increased activation of MMP-9 and thereby increasing the density of DNA-fragmented cells [65]. These data show the reversal of the anti-edematous effects of EPO by tPA and confers MMP-9 unfavorably affects neuronal injury [65]. Moreover, tPA alone had no impact on BBB permeability and EPO alone reduced brain edema without IgG extravasation; therefore, the question arises regarding the mediators responsible for exacerbating $\mathrm{BBB}$ integrity during co-treatment of tPA with EPO.

On a related note, the penetration of EPO across the $\mathrm{BBB}$ has become a central issue. Therefore, focus has been placed on the development of EPO derivatives, which are better able to penetrate across the BBB, such as MK-X, which had a significantly higher accumulation of EPO in the brain at $3 \mathrm{~h}$ compared to the slower time-dependent accumulation in EPO-treated rats [62]. Additionally, another area of interest involves adopting routes of administration that better boost permeability, such as treatment in combination FUS with MBs or intra-nasal administration, opposed to systemic administration $[63,64]$.

Taken together, EPO protects neurons from injury following cerebral $\mathrm{I} / \mathrm{R}$, which is in part mediated by reducing the BBB leakage; however, further studies are warranted to fully elucidate the underlying mechanisms of $\mathrm{BBB}$ disruption. Thus far, the majority of literature demonstrates EPO treatment attenuates the I/R-elicited upregulation of MMP-9 and MMP-2 and prevents the degradation of tight junction proteins. Findings for in vivo studies are summarized in Tables 5 and 6 . Findings for in vitro studies are summarized in Table 7.

\section{Microglia and Astrocyte Activation}

Microglia and astrocytes are abundantly expressed following cerebral I/R injury. Microglia can be activated into 2 polarized states: M1, known to promote inflammatory injury, and M2, known to exert brain protective effects. EPO induces microglial polarization toward the M2 phenotype [74]. As has previously been reported in literature, astrocytes and microglia undergo hypertrophy and hyperplasia following cerebral I/R injury; however, EPO and MEPO similarly decreased the production of new astrocytes and microglia in the peri-infarction 14 days after cerebral I/R injury [66]. The reduction of gliogenesis subsequently contributes to neurogenesis and angiogenesis [66]. Similarly, EPO treatment with MBs/FUS attenuated glial fibrillary acidic protein expression and CD11b staining detected ramified microglia, therefore taken together both play an integral role in reducing neurological deficits [64].

Reactive astrocytes form glial scars, which inhibit axonal regeneration, as one study noted an increased expression of beta amyloid precursor protein, a marker of axonal injury, following tMCAO. Subsequently, EPO reduced demyelination, astrocyte activation, and the protein level of beta amyloid precursor protein [61]. Additionally, EPO inhibited the elevated myelin inhibitors of axonal regrowth, neurite growth inhibitor-A (NogoA), and myelin-associated glycoprotein (MAG), thereby diminishing axonal injury 14 days after MCAO in the brain of adult mice [61].

In vitro studies further corroborate in vivo findings and provide an insight into the molecular and cellular mechanisms of EPO-mediated brain protection. EPO exerted protective effects on astrocytic swelling after oxygen deprivation (OGD) and reoxygenation. EPO inhibited the overactivation of MAPK pathways, suppressed the overabundance of aquaporin4 (AQP4), and thereby reduced astrocytic swelling induced by OGD. Therefore, reducing 


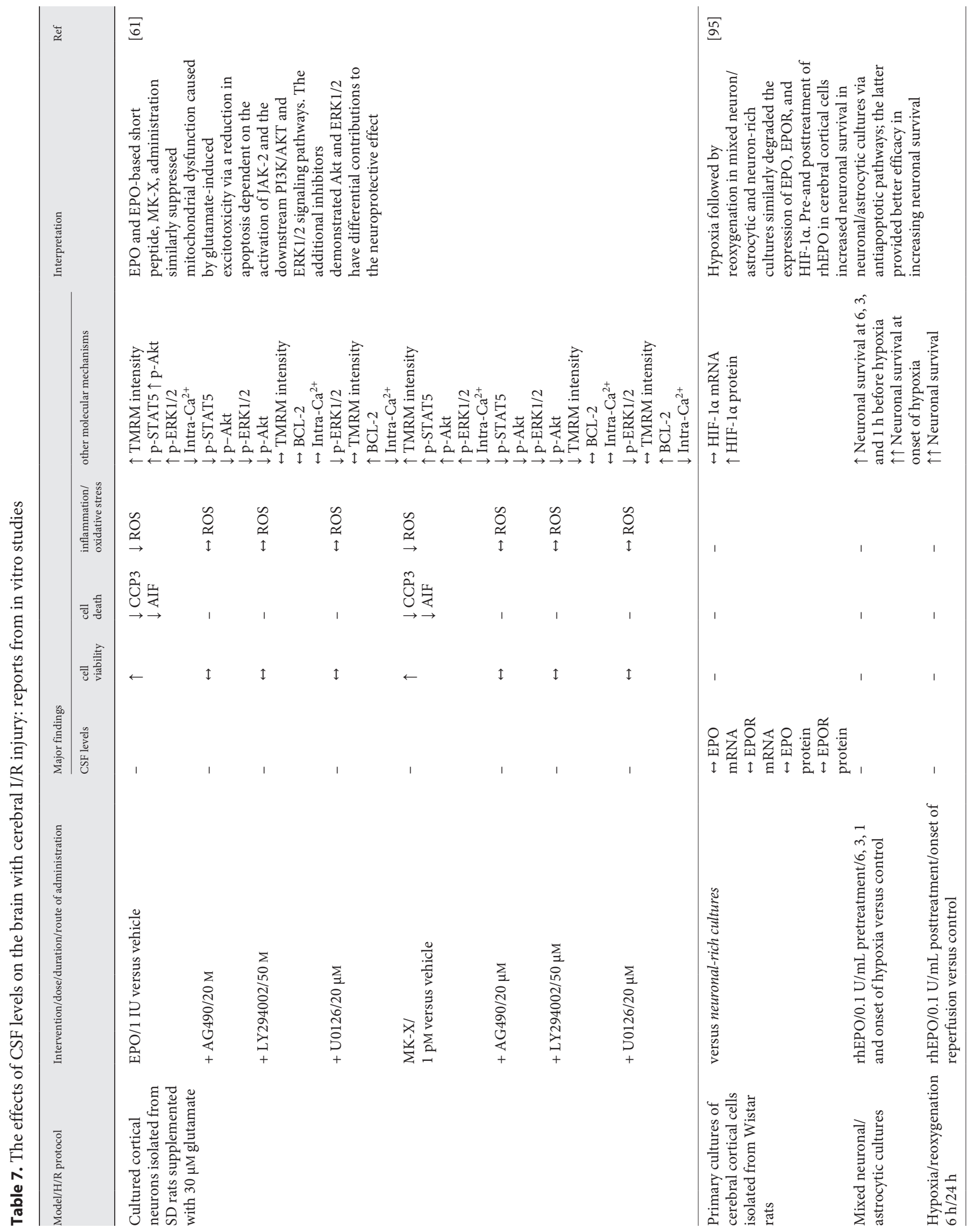




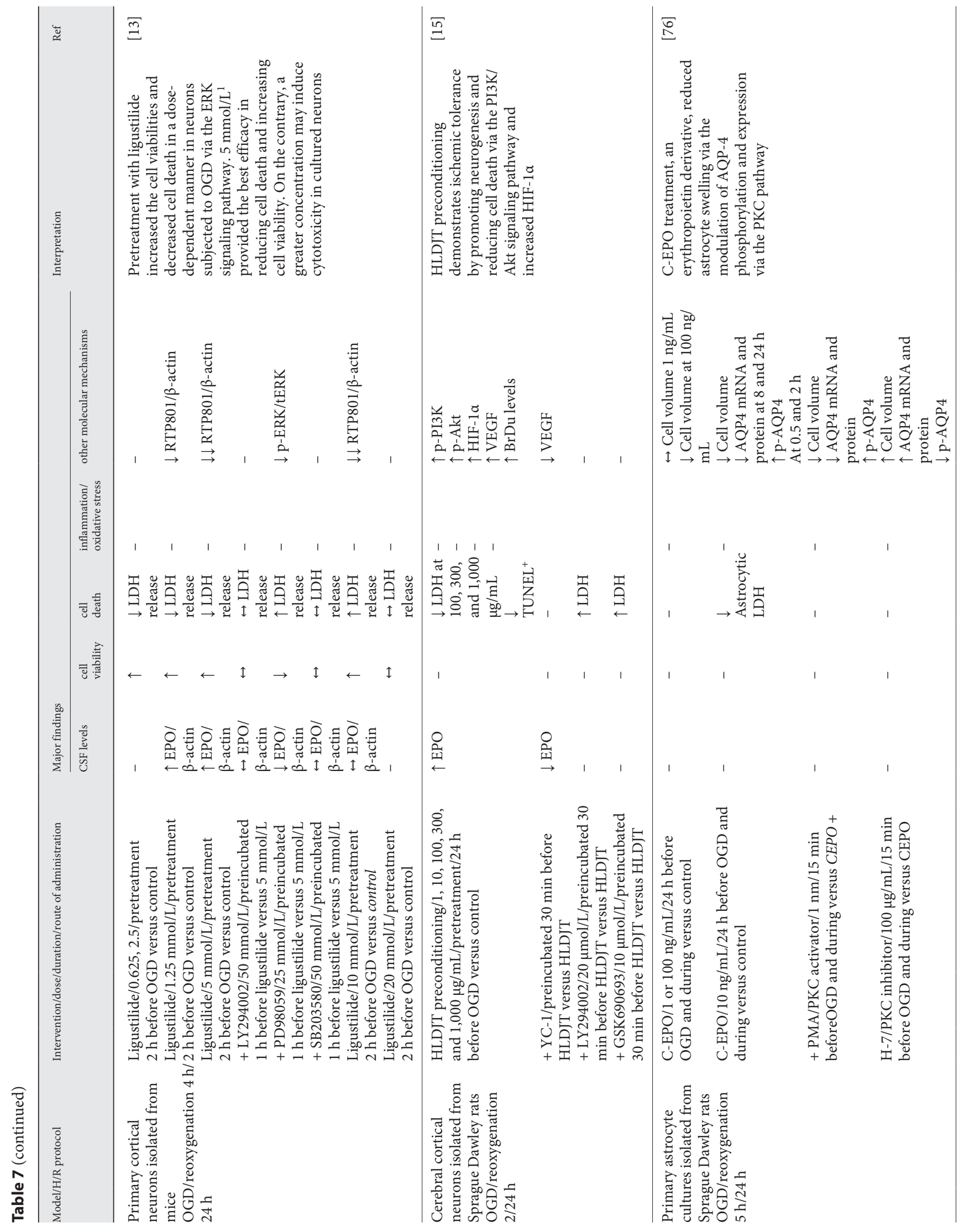




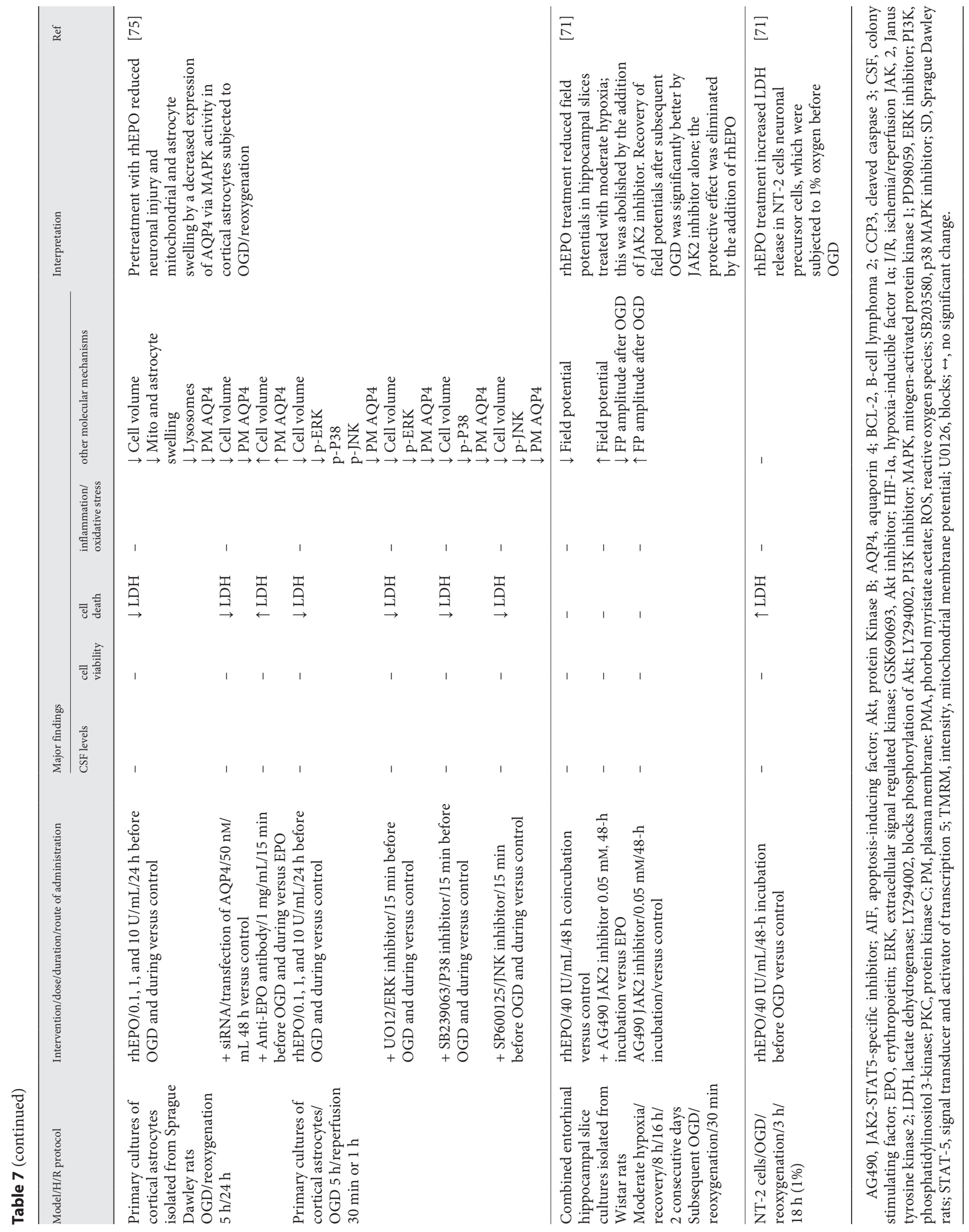


MAPK-dependent AQP4 abundance in the plasma membrane is involved in EPO-mediated brain protection and enables the anti-edemic effects of EPO [75]. Equally, C$\mathrm{EPO}$, an EPO derivative, effectively mitigated astrocytic swelling induced by $\mathrm{I} / \mathrm{R}$ injury through modulating the expression of $\mathrm{AQP} 4$ via the protein kinase $\mathrm{C}(\mathrm{PKC})$ pathway. This is implied as phorbol myristate acetate, an activator of $\mathrm{PKC}$, further promoted the C-EPO-mediated decrease of AQP4 phosphorylation and downregulation of expression and attenuation of astrocytic swelling. Conversely, HI-7, an inhibitor of PKC, eradicated these brain protective effects [76]. A vast amount of literature has addressed the activation of astrocytes and microglia following cerebral I/R injury; however, EPO-mediated reduction of activated microglia and astrocytes is widely recognized, but the clear underlying cellular and molecular pathways are yet to be elucidated. Findings for in vivo studies are summarized in Tables 5 and 6 . Findings for in vitro studies are summarized in Table 7.

\section{Angiogenesis}

EPO modulates angiogenesis in the ischemic brain; this is supported by both in vivo and in vitro findings. The stimulation of neovascularization by EPO treatment exerts brain protective effects that may preserve perfusion in metabolically compromised tissue. Previous literature has addressed the role of angiogenesis following cerebral I/R injury. Zhang et al. [66] investigated the effects of EPO and MEPO in a mouse model of transient focal cerebral ischemia. An increase in lectin ${ }^{+} / \mathrm{BrdU}^{+}$co-localized cells was observed in the surrounding areas of infarction and thereby validated EPO and MEPO further increase angiogenesis. Additionally, the underlying cellular pathway of MEPO/EPO-mediated angiogenesis is potentially increased by activation of Wnt5a, EphrinB2, and EphB4 pathways, which provides the basis for neurogenesis and tissue regeneration [66]. EphB4/EphrinB2 signaling is associated with endothelial cell growth, survival, migration, assembly, and angiogenesis [66]. Moreover, the PI3K/Akt and ERK1/2 pathways stimulate MMP-2 and MMP-9 production, key regulators of EPO-mediated angiogenesis. Notably, an increase in the expression of vascular endothelial growth factor and brain-derived neurotrophic factor has been associated with EPO-enhanced angiogenesis [77]. Overall, the findings emphasize EPO and EPO analogs effectively provide a permissive microenvironment for neural plasticity during stroke recovery; however, the underlying pathways are likely incredibly complex and require further research. Findings for in vivo studies are summarized in Tables 5 and 6 .

\section{Effects of EPO and GCSF on Stroke Outcome from Clinical Studies}

The favorable in vivo and in vitro findings led to the rationale for clinical use of GCSF and EPO in cerebral I/R injury; however, several challenges remain in translating the experimental success of CSFs (EPO and GCSF) in the clinical arena. There are several in vitro studies proving that the antiapoptotic, anti-inflammatory, angiogenic, and neurogenic effects of EPO and GCSF are exerted via JAK/STAT, MAPK, PI3K/Akt, and ERK1/2 pathways $[57,62,71]$. However, a translation to the clinic has been hindered by several obstacles: the dosage conversion from bench to bedside, off-target effects, problems in crossing the $\mathrm{BBB}$, a short half-life, low selectivity, and delivery [78]. Additionally, higher doses of EPO were correlated with severe systemic side effects, for instance, red cell aplasia, hypertension, and thrombosis. The translational disappointments have fueled immense pessimism; however, clinical promise remains for growth factors, GCSF and EPO.

Despite the interest of clinicians, there are few trials published to date investigating the efficacy of EPO and GCSF in the human ischemic brain. In the models of experimental stroke and cerebral hypoxia/ischemia, EPO and GCSF displayed regenerative and brain protective effects, including recruiting neural progenitors, reducing cerebral edema and neurological deficits, and improving survival rates; therefore, they were considered candidate treatments for enhancing stroke recovery. Consequently, phase I/II clinical trials were conducted to determine whether similar brain protective effects can be attained in ischemic human brains.

With regard to rhGCSF, among the few trials published to date, "The Stem Cell Trial of Recovery Enhancement after Stroke" was a randomized controlled pilot study to determine the safety of GCSF in 36 patients with recent (7-30 days postictus) ischemic stroke and its effect on circulating CD $34^{+}$cells [79]. Patients were randomized to either receive a subcutaneous injection of rhEPO or placebo (saline) in a dose-escalation design. The primary outcome was peak circulating blood CD $34^{+}$count, and thereafter, safety was assessed. GCSF administration was feasible, safe, and well tolerated and effectively mobilized bone $\mathrm{CD} 34^{+}$cells in patients with recent ischemic stroke; however, the functional outcome remained uncertain [79]. Similarly, a preliminary study sought to determine the feasibility, safety, and efficacy of GCSF to treat acute stroke in a small, randomized, blinded controlled trial. Ten patients with acute cerebral infarction 


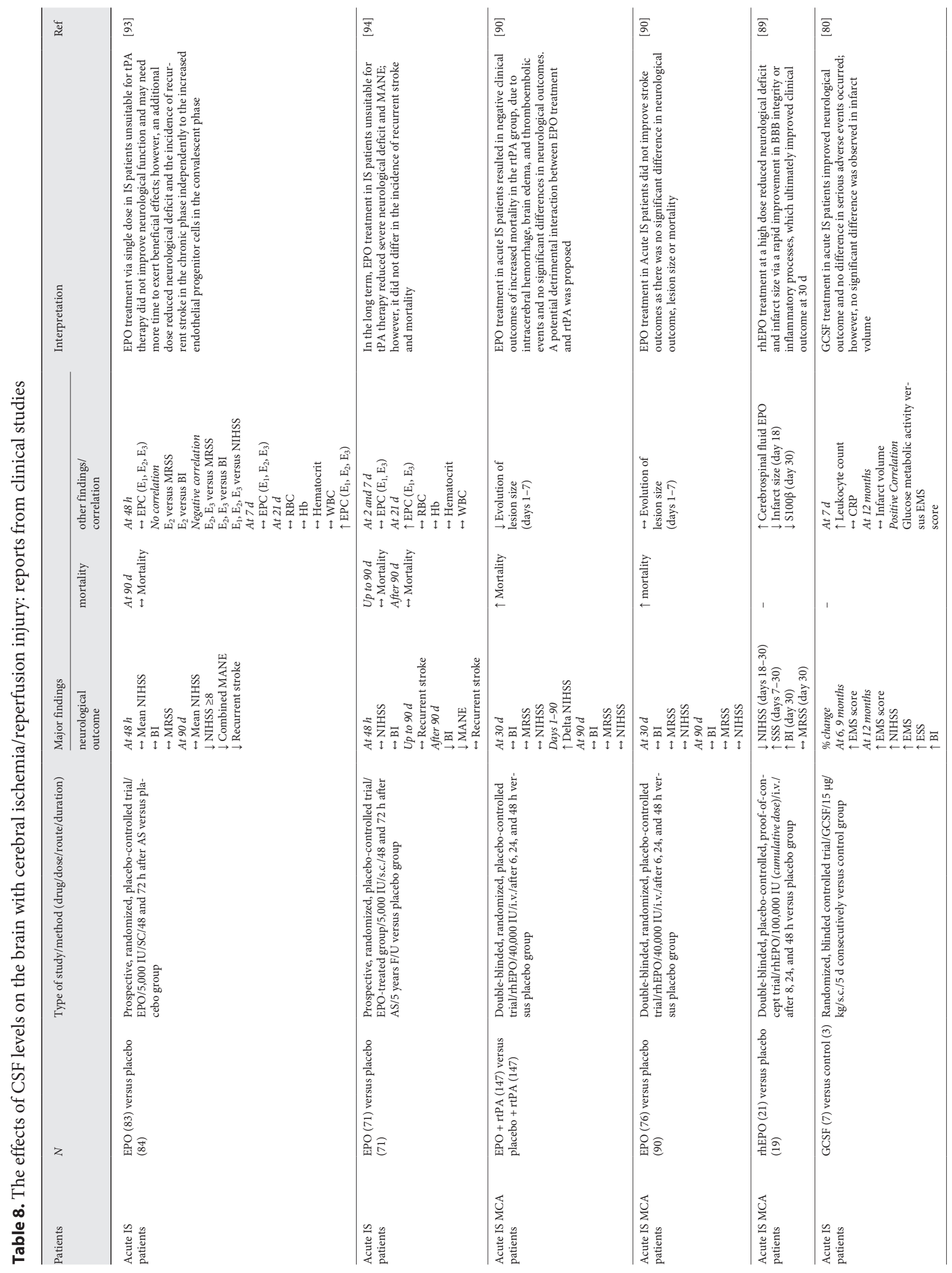




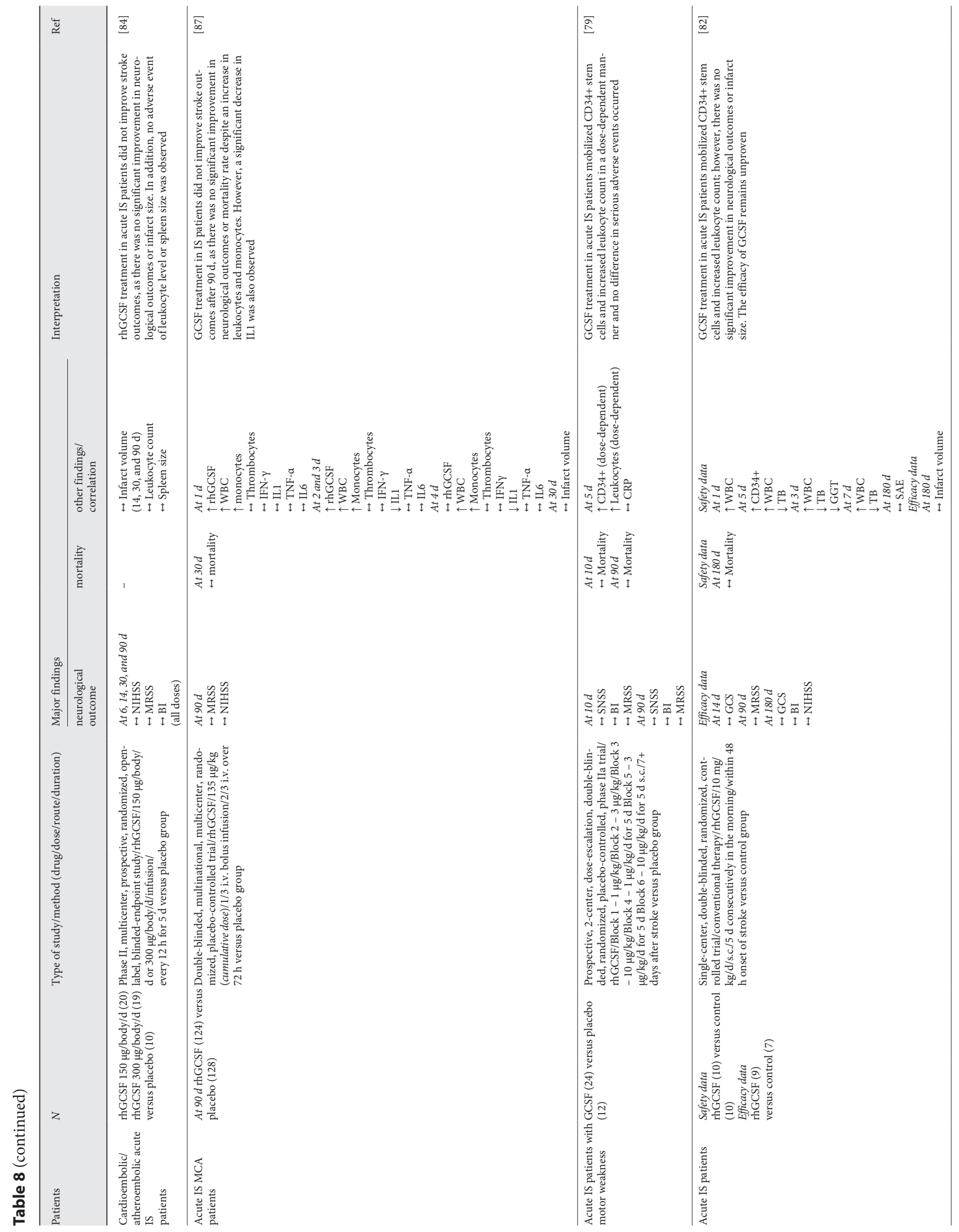




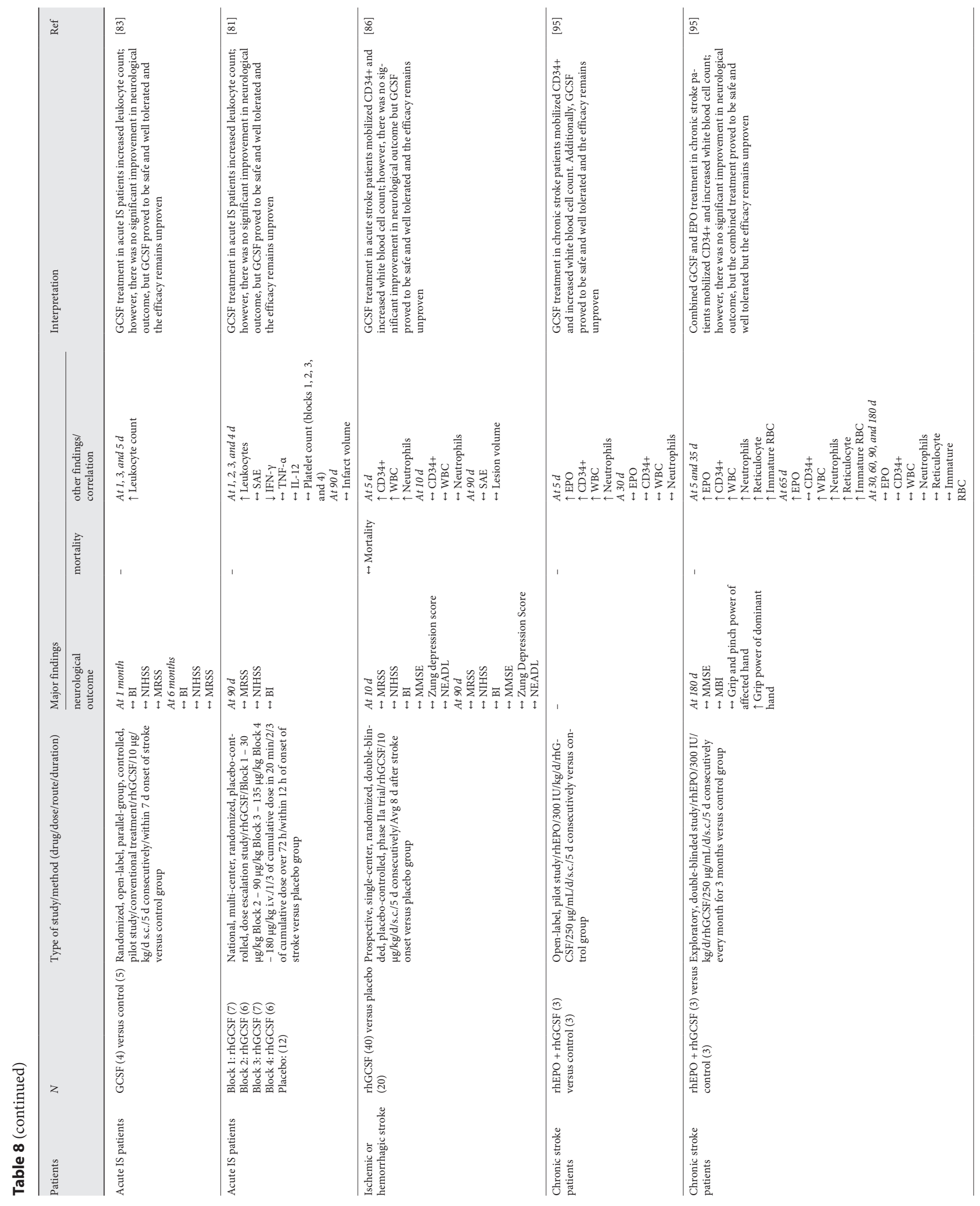




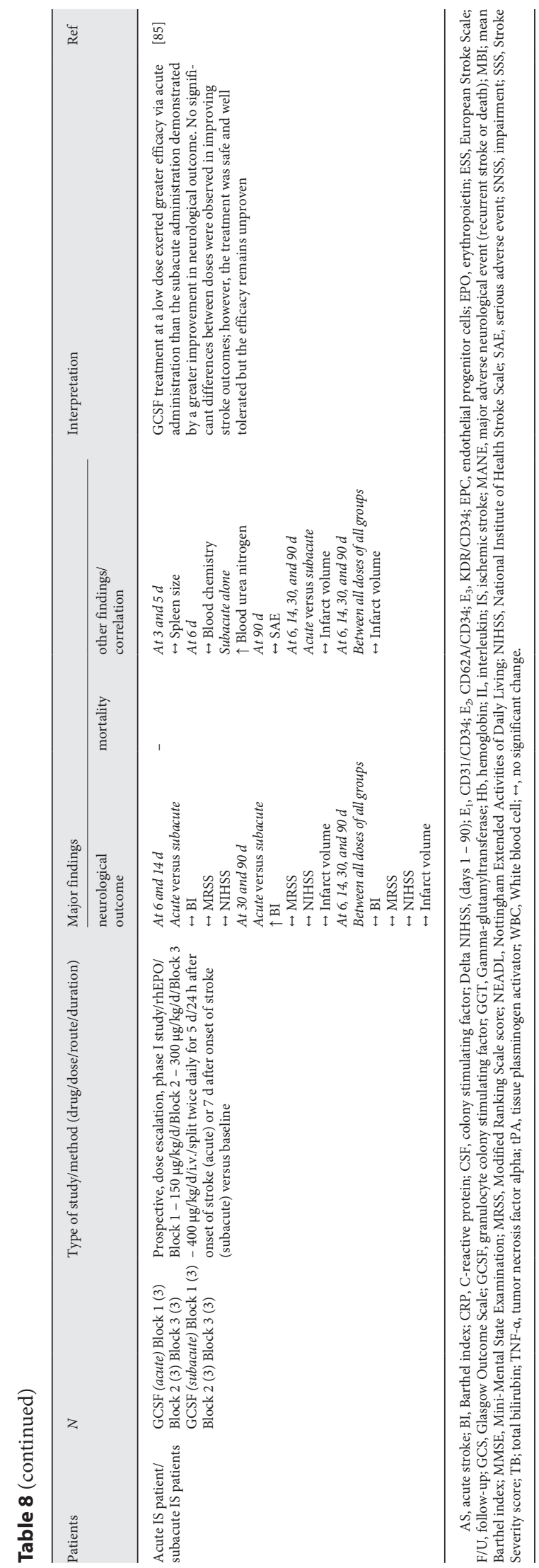

(middle cerebral artery territory) who presented within 7 days of onset were recruited, in which the GCSF group received GCSF injections ( $15 \mu \mathrm{g} / \mathrm{kg}$ per day) for 5 days. The primary outcome was clinical improvement assessed in 12-month follow-up through 4 clinical scales: National Institutes of Health Stroke Scale (NIHSS), European Stroke Scale (ESS), ESS Motor Subscale (EMS), and Barthel index (BI). Neurological functioning using PET to measure cerebral uptake of fluorodeoxyglucose in the cortical areas surrounding the ischemic core was also assessed. GCSF proved to be feasible, safe, and well tolerated [80].

GCSF was further validated to be a promising candidate for stroke treatment by a multicenter, randomized, placebo-controlled dose escalation study. Forty-four patients with recent ischemic stroke ( $12 \mathrm{~h}$-time window) were recruited and randomized to either placebo or 4 sequentially escalating dose groups, in which GCSF was administered intravenously. There is major concern regarding the hematologic effects of GCSF, the elevation of leukocytosis, and GCSF-mediated effects on platelets may involve coagulation and alter bleeding risks. GCSF was well tolerated at high dosages in patients with acute ischemic stroke, even with larger baseline diffusion-weighted imaging lesions, and that a substantial increase in leukocytes appeared not to be problematic in stroke patients [81].

Alasheev et al. [82] conducted a randomized controlled trial of 20 adult patients with ischemia in the carotid region within $48 \mathrm{~h}$ of onset, 10 patients were administered subcutaneous GCSF injections (10 mg/kg/day) and conventional therapy for 5 days. In this study, rtPA may re-establish blood flow in the penumbra region, and therefore, the benefit that GCSF could provide is diluted, demonstrating the difficulty of improving the outcome on top of the effect of rtPA, caused by a ceiling effect of thrombolysis. The primary outcome was motor function, as measured by the modified Rankin Scale (mRS) 180 days poststroke, thereafter safety was assessed [82]. Although the sample size was small, the results were comparable with previously mentioned studies, as the safety and tolerance was proven [82].

Similarly, Prasad et al. [83] reported that GCSF administered $10 \mu \mathrm{g} / \mathrm{kg}$ daily for 5 days appeared to be safe and well tolerated in 5 patients aged 35-75 years with acute ischemic stroke in accordance with other published GCSF trials in stroke patients; however, this study had a small sample size; therefore, it did not have the power to assess the efficacy of GCSF on functional outcome. Sample size also restricted the clinical trials of low-dose GCSF intra- 
venous administration effectively assessing functional outcome; however, these studies conferred the safety of GCSF $[84,85]$. So, the efficacy of GCSF, once again, remained uncertain. GCSF enhances revascularization and reduces cerebral inflammation and the mentioned phase II clinical trials of intravenous transplantation of autologous bone marrow stem cells have conveyed safety and tolerability [81, 84-86].

While some clinical trials have confirmed the feasibility, safety, and efficacy of GCSF administration for stroke, the exact impact remains disputed. As previously mentioned, phase IIa dose escalation study indicated possible efficacy in humans [81], and thereby, a large phase IIb trial was designed to detect the clinical efficacy in acute ischemic stroke patients [87]. However, a cumulative dose of $135 \mu \mathrm{g} / \mathrm{kg}$ body weight rhGCSF was tested over $72 \mathrm{~h}$ against placebo in 328 patients in a multinational, multicenter, randomized, and placebo-controlled trial and failed to meet primary and secondary endpoints. The primary endpoint was a difference of the mRS score at day 90 between GCSF- and placebo-treated patients; the secondary endpoint was a difference in NIHSS score at day 90 between GCSF- and placebo-treated patients. Additionally, GCSF showed no efficacy at day 30 for additional endpoints: mortality, BI, or infarct size. Regrettably, the reasons for the failure of GCSF remain obscure. Worthy of note, however, was the increase in leukocytes and monocytes, which might have led to blood coagulation and an increased risk of thromboembolic events [87]. All in all, GCSF did not improve stroke outcome after 90 days when applied as 3-day intravenous therapy, despite bolstering evidence from preclinical and clinical data. This strengthens the notion of a principal issue in translating findings from the animal laboratory to clinical stroke patients whose basis is currently not understood [87]. Nevertheless, it is premature to dismiss the importance of preclinical animal models until studies are undertaken with greater methodological rigor, as stated by Phillip et al. [88], the quality and adequacy can be significantly improved.

As regards EPO, similar to GCSF, was hailed an auspicious therapeutic strategy according to studies conducted in animal models of stroke; however, the clinical trials were swiftly aborted in phase II. Therefore, cautious optimism should, once again, be employed in the use of EPO for human stroke. Ehrenreich et al. [89] conducted a trial of 2 parts, the safety study conferred no safety concerns. Subsequently, rhEPO was administered intravenously $\left(3.3 \times 10^{4} \mathrm{IU} / 50 \mathrm{~mL} / 30 \mathrm{~min}\right)$ once daily for the first 3 days after stroke in 13 patients. Thereafter, a double-blind ran- domized proof-of-concept trial was conducted involving 40 patients (symptom onset $<8 \mathrm{~h}$ ) randomized to receive either rhEPO or saline, and clinical improvement was assessed in a 30-day follow up. The findings regarding the efficacy of rhEPO remained consistent with animal models of ischemic brain injury as the rhEPO-treated group recovered significantly better with respect to the clinical endpoint of stroke and outcome scales. This trial provided encouraging findings, as a high dose of rhEPO intravenously injected significantly reduced neurological deficits and ameliorated stroke-related disability at 30 days [89].

The German Multicenter EPO Stroke Trial, a phase II/ III trial [90], was conducted to reproduce the promising findings of the Gottingen EPO Stroke Study [89]. Despite the strong preclinical and clinical pilot study data and its success in phase I and phase II trials, rhEPO failed to improve clinical outcomes in ischemic stroke patients in a double-blind, placebo-controlled, randomized German Multicenter EPO Stroke Trial; thus, it was regarded a negative trial, which raised safety concerns specifically in patients receiving systemic thrombolysis [90]. Within $6 \mathrm{~h}$ of symptom onset, at 24 and $48 \mathrm{~h}$, either a high dose of EPO was infused intravenously (40,000 IU each) or saline was administered in 460 patients. Primary outcome BI and all other outcome measures failed to show any improvement, and a higher mortality rate was observed in the EPO-treated group, particularly those pretreated with thrombolysis. Unfortunately, the 90-day follow-up indicated that EPO-treated patients had an increased risk of intracerebral hemorrhage, brain edema, thromboembolic events, and death. Unexpectedly, a high number of patients received rtPA (violating the original protocol); therefore, the authors speculated the increased mortality may be due to the complication caused by the interaction of rtPA and EPO. Worth noting, however, this interaction cannot be considered the sole culprit underlying the failure of EPO in clinical trials, as EPO was shown to increase risk for myocardial infarction and cardiovascular events in patients with anemia [91] and promote tumor formation [92] as well as the previously stated stimulation of hematopoietic effects. Nevertheless, negative trials, like the German multicenter trial, should not discourage researchers from pursuing EPO/EPO variants but rather should encourage new studies in which researchers scrutinize their study design in advance to prevent fatal errors and strict adherence to all safety protocols is obligatory.

EPO increased the circulating levels of endothelial progenitor cells (EPCs) related to prognostic outcomes in ischemic stroke patients [93]. Thus, a group of research- 
ers explored the safety and efficacy of EPO treatment in boosting circulating EPC levels and improving 90-day clinical outcome. A total of 167 patients were randomized to receive either EPO therapy (5,000 IU each time, subcutaneously) at 48 and $72 \mathrm{~h}$ after acute ischemic, or serve as a placebo [93]. EPO administration significantly boosted circulating EPC levels and was strongly associated with favorable 90-day clinical outcomes after IS [93]. Worthy of note, however, although the findings of this trial are contradictory to previously stated German multicenter trial, subgroup analysis indicates EPO therapy improved 90-day clinical outcome of the non-tPA patients, and thereby, partially consistent results are found between these 2 trials, albeit the reason remains uncertain.

Intriguingly, the secondary objective by Yip et al. [93] was to evaluate the long-term (5 years) outcome of EPOtreated patients; this yielded several striking findings reported by Tsai et al. [94]. EPO treatment ameliorated long-term clinical outcome in patients after acute ischemic stroke; this is evident by severely reduced neurological deficits and long-term MANE compared to placebo-control patients [94]. This trial further conferred EPO as an alternative therapeutic choice for acute IS patients who are not candidates for $\mathrm{PPA}$. Nevertheless, this followup was not without limitations, a few of which are that the sample size was small and the incompleteness of followup data casts doubt regarding the interpretation of differences in clinical outcome.

Translation to the clinic has been hindered by several obstacles: the dosage conversion from bench to bedside, off-target effects, problems in crossing the $\mathrm{BBB}$, a short half-life, low selectivity, and delivery [78]. One of the most neglected facts when focusing on experimental setups are issues like comorbidities and age. Age is considered one of the most significant risk factors for cerebral ischemia. In humans, age plays a major role in recovery and neurological outcome of stroke patients. To date, there are no explicit studies that have investigated EPO in combination with age and comorbidities. Therefore, future preclinical studies aiming at developing new therapeutic strategies for ischemic stroke must consider age in animal models, in order to better translate experimental findings into clinics.

The translational disappointments have fueled immense pessimism; however, clinical promise remains for growth factors, GCSF and EPO. Despite the initial skepticism as a result of negative trials, researchers continue to justify further projects and thereby many clinical trials for both growth factors and analogs without hematopoietic effects are currently underway. Of particular importance in relation to the safety and tolerability is that authors must adhere to comprehensive safety protocols and must not neglect to consider comorbidities to avoid fatal errors. All findings are summarized in Table 8 .

\section{Conclusion}

Cerebral I/R injury is a deteriorative process, which can culminate oxidative stress, mitochondrial dysregulation, leukocyte infiltration, BBB disruption, brain inflammation, and increased neuronal apoptosis, ultimately leading to infarction and subsequent cognitive impairments. During the last 2 decades, EPO and GCSF have emerged as potent inhibitors of neuronal demise under acute and chronic pathological conditions. The above outlined positive data from in vivo and in vitro studies of GCSF, EPO, and its variants confer that they act on the aforementioned pathways to exert brain protection following cerebral I/R injury. EPO and GCSF can be considered double-edged sword combatting ischemic damage but not a miraculous intervention due to hematopoietic consequences. Higher doses of EPO were correlated with severe systemic side effects. Therefore, the development of MK-X, CEPO, AEPO, and MEPO and other EPO variants for brain protection conceptually devoid of side effects, ignites optimism for a robust poststroke therapy. To date, only a minority of clinical trials have been conducted related to EPO variants for the treatment of cerebral I/R injury. Undoubtedly, further research is highly warranted, albeit the risk-benefit ratio should be carefully considered. Translation to clinical trials has been impeded by several obstacles; therefore, researchers must scrutinize their study design in advance to prevent fatal errors and adhere to comprehensive safety protocols. Future studies are highly warranted to validate and optimize the dose and route of administration of GCSF, EPO, and its analogs, as we continue the search for a robust and effective poststroke therapy.

\section{Statement of Ethics}

Ethical approval was not required since this paper does not involve animals or human experiments.

\section{Conflict of Interest Statement}

The authors declare that there is no conflict of interest. 


\section{Funding Sources}

This work was supported by the Senior Research Scholar grant from the National Research Council of Thailand (S.C.C.); an NSTDA Research Chair Grant from the National Science and Technology Development Agency Thailand (N.C.), and a Chiang Mai University Excellence Center Award (N.C.).

\section{Author Contributions}

N.C. and S.C.C.: conception. A.M.R.P., N.A., and N.C., and S.C.C.: drafting of the manuscript, revision of the manuscript, and final approval.

\section{References}

1 Writing Group Members; Mozaffarian D, Benjamin EJ, Go AS, Arnett DK, Blaha MJ, et al. Heart disease and stroke statistics-2016 update: a report from the American Heart Association. Circulation. 2016 Jan 26;133(4): e38-360.

2 GBD 2016 Stroke Collaborators. Global, regional, and national burden of stroke, 19902016: a systematic analysis for the Global Burden of Disease Study 2016. Lancet Neurol. 2019 May; 18(5):439-58.

3 Duffis EJ, Al-Qudah Z, Prestigiacomo CJ, Gandhi C. Advanced neuroimaging in acute ischemic stroke: extending the time window for treatment. Neurosurg Focus. 2011 Jun; 30(6):E5.

4 Yoo AJ, Pulli B, Gonzalez RG. Imaging-based treatment selection for intravenous and intraarterial stroke therapies: a comprehensive review. Expert Rev Cardiovasc Ther. $2011 \mathrm{Jul}$ 9(7):857-76.

5 Fisher M, Albers GW. Advanced imaging to extend the therapeutic time window of acute ischemic stroke. Ann Neurol. 2013 Jan;73(1): 4-9.

6 DT LL, Tuyen PNK, Vu TY. Ischemia-reperfusion injury in the brain: mechanisms and potential therapeutic strategies. Biochem Pharmacol. 2016;5(4):213.

7 Bath PM, Sprigg N, England T. Colony stimulating factors (including erythropoietin, granulocyte colony stimulating factor and analogues) for stroke. Cochrane Database Syst Rev. 2013 Jun 24(6):CD005207.

8 Wu MY, Yiang GT, Liao WT, Tsai AP, Cheng YL, Cheng PW, et al. Current mechanistic concepts in ischemia and reperfusion injury. Cell Physiol Biochem. 2018;46(4):1650-67.

9 Mu D, Chang YS, Vexler ZS, Ferriero DM. Hypoxia-inducible factor 1alpha and erythropoietin upregulation with deferoxamine salvage after neonatal stroke. Exp Neurol. 2005 Oct;195(2):407-15.

10 Zhu H, Sun S, Li H, Xu Y. Cerebral ischemic tolerance induced by 3-nitropropionic acid is associated with increased expression of erythropoietin in rats. J Huazhong Univ Sci Technol Med Sci. 2006;26(4):440-3.

11 Gu GJ, Li YP, Peng ZY, Xu JJ, Kang ZM, Xu WG, et al. Mechanism of ischemic tolerance induced by hyperbaric oxygen preconditioning involves upregulation of hypoxia-inducible factor-1alpha and erythropoietin in rats. J Appl Physiol. 2008 Apr;104(4):1185-91.
12 Gao L, Ji X, Song J, Liu P, Yan F, Gong W, et al. Puerarin protects against ischemic brain injury in a rat model of transient focal ischemia. Neurol Res. 2009 May;31(4):402-6.

13 Wu XM, Qian ZM, Zhu L, Du F, Yung WH, Gong Q, et al. Neuroprotective effect of ligustilide against ischaemia-reperfusion injury via up-regulation of erythropoietin and downregulation of RTP801. Br J Pharmacol. 2011 Sep;164(2):332-43.

14 Zhang Q, Bian H, Li Y, Guo L, Tang Y, Zhu $\mathrm{H}$. Preconditioning with the traditional Chinese medicine Huang-Lian-Jie-Du-Tang initiates HIF-1 1 -dependent neuroprotection against cerebral ischemia in rats. J Ethnopharmacol. 2014 Jun 11;154(2):443-52.

15 Zhang L, Wang H, Wang T, Jiang N, Yu P, Chong Y, et al. Ferulic acid ameliorates nerve injury induced by cerebral ischemia in rats. Exp Ther Med. 2015 Mar;9(3):972-6.

16 Wei Y, Hong H, Zhang X, Lai W, Wang Y, Chu K, et al. Salidroside inhibits inflammation through PI3K/Akt/HIF signaling after focal cerebral ischemia in rats. Inflammation. 2017 Aug;40(4):1297-309.

17 Wan J, Wan H, Yang R, Wan H, Yang J, He Y, et al. Protective effect of Danhong Injection combined with Naoxintong Capsule on cerebral ischemia-reperfusion injury in rats. J Ethnopharmacol. 2018 Jan 30;211:348-57.

$18 \mathrm{Wu}$ W, Zhong W, Lang B, Hu Z, He J, Tang $\mathrm{X}$. Thrombopoietin could protect cerebral tissue against ischemia-reperfusion injury by suppressing NF- $\kappa \mathrm{B}$ and MMP-9 expression in rats. Int J Med Sci. 2018;15(12):1341-8.

19 Taylor SK. Is recombinant human erythropoietin (rh-epo) more than just a treatment of anemia in cancer and chemotherapy? Med Hypotheses. 2003 Jan;60(1):89-93.

20 Schabitz WR, Schneider A. New targets for established proteins: exploring G-CSF for the treatment of stroke. Trends Pharmacol Sci. 2007 Apr;28(4):157-61.

21 Jin WN, Shi SX, Li Z, Li M, Wood K, Gonzales RJ, et al. Depletion of microglia exacerbates postischemic inflammation and brain injury. J Cereb Blood Flow Metab. 2017 Jun;37(6): 2224-36.

22 Schneider A, Krüger C, Steigleder T, Weber $\mathrm{D}$, Pitzer C, Laage R, et al. The hematopoietic factor G-CSF is a neuronal ligand that counteracts programmed cell death and drives neurogenesis. J Clin Invest. 2005 Aug;115(8): 2083-98.
23 Maiese K, Li F, Chong ZZ. Erythropoietin in the brain: can the promise to protect be fulfilled? Trends Pharmacol Sci. 2004 Nov; 25(11):577-83.

24 Malhotra S, Savitz SI, Ocava L, Rosenbaum DM. Ischemic preconditioning is mediated by erythropoietin through PI-3 kinase signaling in an animal model of transient ischemic attack. J Neurosci Res. 2006 Jan;83(1):19-27.

25 Chong ZZ, Kang JQ, Maiese K. Erythropoietin fosters both intrinsic and extrinsic neuronal protection through modulation of microglia, Akt1, Bad, and caspase-mediated pathways. Br J Pharmacol. 2003 Mar;138(6): 1107-18.

26 Genc S, Koroglu TF, Genc K. Erythropoietin and the nervous system. Brain Res. 2004 Mar 12;1000(1-2):19-31.

27 Li HD, Li M, Shi E, Jin WN, Wood K, Gonzales $\mathrm{R}$, et al. A translocator protein $18 \mathrm{kDa}$ agonist protects against cerebral ischemia/reperfusion injury. J Neuroinflammation. $2017 \mathrm{Jul}$ 28;14(1):151.

28 Yu X, Shacka JJ, Eells JB, Suarez-Quian C, Przygodzki RM, Beleslin-Cokic B, et al. Erythropoietin receptor signalling is required for normal brain development. Development. 2002 Jan;129(2):505-16.

29 Sevimli S, Diederich K, Strecker JK, Schilling M, Klocke R, Nikol S, et al. Endogenous brain protection by granulocyte-colony stimulating factor after ischemic stroke. Exp Neurol. 2009 Jun;217(2):328-35.

30 Siren AL, Knerlich F, Poser W, Gleiter CH, Bruck W, Ehrenreich H. Erythropoietin and erythropoietin receptor in human ischemic/ hypoxic brain. Acta Neuropathol. 2001 Mar; 101(3):271-6.

31 Wang JY, Shen J, Gao Q, Ye ZG, Yang SY, Liang $\mathrm{HW}$, et al. Ischemic postconditioning protects against global cerebral ischemia/reperfusion-induced injury in rats. Stroke. 2008 Mar;39(3):983-90.

32 Schaar KL, Brenneman MM, Savitz SI. Functional assessments in the rodent stroke model. Exp Transl Stroke Med. 2010 Jul 19;2(1):13.

33 Liew HK, Kuo JS, Wang JY, Pang CY. Granulocyte-colony stimulating factor increases cerebral blood flow via a NO surge mediated by Akt/eNOS pathway to reduce ischemic injury. ScientificWorldJournal. 2015; 2015: 657932. 
34 Solaroglu I, Tsubokawa T, Cahill J, Zhang JH. Anti-apoptotic effect of granulocyte-colony stimulating factor after focal cerebral ischemia in the rat. Neuroscience. 2006 Dec 28; 143(4):965-74.

35 Shyu WC, Lin SZ, Yang HI, Tzeng YS, Pang CY, Yen PS, et al. Functional recovery of stroke rats induced by granulocyte colonystimulating factor-stimulated stem cells. Circulation. 2004 Sep 28;110(13):1847-54.

36 Lee ST, Chu K, Jung KH, Ko SY, Kim EH, Sinn DI, et al. Granulocyte colony-stimulating factor enhances angiogenesis after focal cerebral ischemia. Brain Res. 2005 Oct 5;1058(1-2): $120-8$

37 Komine-Kobayashi M, Zhang N, Liu M Tanaka R, Hara H, Osaka A, et al. Neuroprotective effect of recombinant human granulocyte colony-stimulating factor in transient focal ischemia of mice. J Cereb Blood Flow Metab. 2006 Mar;26(3):402-13.

38 Yanqing Z, Yu-Min L, Jian Q, Bao-Guo X Chuan-Zhen L. Fibronectin and neuroprotective effect of granulocyte colony-stimulating factor in focal cerebral ischemia. Brain Res. 2006 Jul 7;1098(1):161-9.

39 Sehara Y, Hayashi T, Deguchi K, Zhang H, Tsuchiya A, Yamashita T, et al. Potentiation of neurogenesis and angiogenesis by G-CSF after focal cerebral ischemia in rats. Brain Res. 2007 Jun 2;1151:142-9.

40 Li YG, Liu XL, Zheng CB. Granulocyte colony-stimulating factor regulates JNK pathway to alleviate damage after cerebral ischemia reperfusion. Chin Med J. 2013 Nov; 126(21): 4088-92.

41 Gautier S, Ouk T, Tagzirt M, Lefebvre C, Laprais M, Pétrault $\mathrm{O}$, et al. Impact of the neutrophil response to granulocyte colony-stimulating factor on the risk of hemorrhage when used in combination with tissue plasminogen activator during the acute phase of experimental stroke. J Neuroinflammation. 2014 May 27;11:96.

42 Ghahari L, Safari M, Joghataei MT, Mehdizadeh M, Soleimani M. Effect of combination therapy using hypothermia and granulocyte colony-stimulating factor in a rat transient middle cerebral artery occlusion model. Iran Biomed J. 2014;18(4):239-44.

43 Garcia-Bonilla L, Racchumi G, Murphy M, Anrather J, Iadecola C. Endothelial CD36 contributes to postischemic brain injury by promoting neutrophil activation via CSF3. J Neurosci. 2015 Nov 4;35(44):14783-93.

44 Minnerup J, Sevimli S, Schäbitz WR. Granulocyte-colony stimulating factor for stroke treatment: mechanisms of action and efficacy in preclinical studies. Exp Transl Stroke Med. 2009 Oct 21;1:2.

45 Tobin MK, Bonds JA, Minshall RD, Pelligrino DA, Testai FD, Lazarov O. Neurogenesis and inflammation after ischemic stroke: what is known and where we go from here. J Cereb Blood Flow Metab. 2014 Oct;34(10):1573-84.
46 Mizuma A, Yenari MA. Anti-inflammatory targets for the treatment of reperfusion injury in stroke. Front Neurol. 2017;8:467.

47 Jin R, Yang G, Li G. Inflammatory mechanisms in ischemic stroke: role of inflammatory cells. J Leukoc Biol. 2010 May;87(5):77989.

48 Takano T, Oberheim N, Cotrina ML, Nedergaard M. Astrocytes and ischemic injury. Stroke. 2009 Mar;40(3 Suppl):S8-12.

49 Pandya NM, Dhalla NS, Santani DD. Angiogenesis: a new target for future therapy. Vascul Pharmacol. 2006 May;44(5):265-74.

50 Beck H, Plate KH. Angiogenesis after cerebral ischemia. Acta Neuropathol. 2009 May: 117(5):481-96.

51 Calapai G, Marciano MC, Corica F, Allegra A, Parisi A, Frisina N, et al. Erythropoietin protects against brain ischemic injury by inhibition of nitric oxide formation. Eur J Pharmacol. 2000 Aug 11;401(3):349-56.

52 Bahcekapili N, Uzüm G, Gökkusu C, Kuru A, Ziylan YZ. The relationship between erythropoietin pretreatment with blood-brain barrier and lipid peroxidation after ischemia/reperfusion in rats. Life Sci. 2007 Mar 13;80(14): 1245-51.

53 Liu K, Sun T, Wang P, Liu YH, Zhang LW, Xue YX. Effects of erythropoietin on bloodbrain barrier tight junctions in ischemia-reperfusion rats. J Mol Neurosci. 2013 Feb; 49(2):369-79.

54 Ratilal BO, Arroja MM, Rocha JP, Fernandes AM, Barateiro AP, Brites DM, et al. Neuroprotective effects of erythropoietin pretreatment in a rodent model of transient middle cerebral artery occlusion. J Neurosurg. 2014 Jul;121(1):55-62.

55 Khaksari M, Mehrjerdi FZ, Rezvani ME, Safari F, Mirgalili A, Niknazar S. The role of erythropoietin in remote renal preconditioning on hippocampus ischemia/reperfusion injury. J Physiol Sci. 2017 Jan;67(1):163-71.

56 Chang YS, Mu D, Wendland M, Sheldon RA, Vexler ZS, McQuillen PS, et al. Erythropoietin improves functional and histological outcome in neonatal stroke. Pediatr Res. $2005 \mathrm{Jul}$ 58(1):106-11

57 Gonzalez FF, Abel R, Almli CR, Mu D, Wendland M, Ferriero DM. Erythropoietin sustains cognitive function and brain volume after neonatal stroke. Dev Neurosci. 2009;31(5): 403-11.

58 Ishii T, Asai T, Oyama D, Fukuta T, Yasuda $\mathrm{N}$, Shimizu K, et al. Amelioration of cerebral ischemia-reperfusion injury based on liposomal drug delivery system with asialo-erythropoietin. J Control Release. 2012 May 30; 160(1):81-7.

59 Wang R, Wu X, Liang J, Qi Z, Liu X, Min L, et al. Intra-artery infusion of recombinant human erythropoietin reduces blood-brain barrier disruption in rats following cerebral ischemia and reperfusion. Int J Neurosci. 2015; 125(9):693-702.
60 Zhao H, Wang R, Wu X, Liang J, Qi Z, Liu X, et al. Erythropoietin delivered via intra-arterial infusion reduces endoplasmic reticulum stress in brain microvessels of rats following cerebral ischemia and reperfusion. J Neuroimmune Pharmacol. 2015 Mar;10(1):153-61.

61 Wang R, Zhao H, Li J, Duan Y, Fan Z, Tao Z, et al. Erythropoietin attenuates axonal injury after middle cerebral artery occlusion in mice. Neurol Res. 2017 Jun;39(6):545-51.

62 Yoo SJ, Cho B, Lee D, Son G, Lee YB, Soo Han $\mathrm{H}$, et al. The erythropoietin-derived peptide MK-X and erythropoietin have neuroprotective effects against ischemic brain damage. Cell Death Dis. 2017 Aug 17;8(8):e3003.

63 Yu YP, Xu QQ, Zhang Q, Zhang WP, Zhang $\mathrm{LH}$, Wei EQ. Intranasal recombinant human erythropoietin protects rats against focal cerebral ischemia. Neurosci Lett. 2005 Oct 14; 387(1):5-10.

64 Wu SK, Yang MT, Kang KH, Liou HC, Lu $\mathrm{DH}, \mathrm{Fu} \mathrm{WM}$, et al. Targeted delivery of erythropoietin by transcranial focused ultrasound for neuroprotection against ischemia/reperfusion-induced neuronal injury: a long-term and short-term study. PLoS One. 2014;9(2): e90107.

65 Zechariah A, ElAli A, Hermann DM. Combination of tissue-plasminogen activator with erythropoietin induces blood-brain barrier permeability, extracellular matrix disaggregation, and DNA fragmentation after focal cerebral ischemia in mice. Stroke. 2010 May; 41(5):1008-12.

66 Zhang S-J, Wang R-L, Zhao H-P, Tao Z, Li $\mathrm{J}-\mathrm{C}$, Ju F, et al. MEPO promotes neurogenesis and angiogenesis but suppresses gliogenesis in mice with acute ischemic stroke. Eur J Pharmacol. 2019 Apr 15;849:1-10.

67 Shuaib A, Lees KR, Lyden P, Grotta J, Davalos A, Davis SM, et al. NXY-059 for the treatment of acute ischemic stroke. N Engl J Med. 2007 Aug 9;357(6):562-71.

68 Dang S, Liu X, Fu P, Gong W, Yan F, Han P, et al. Neuroprotection by local intra-arterial infusion of erythropoietin after focal cerebral ischemia in rats. Neurol Res. 2011 Jun;33(5): 520-8.

69 Chiu PC, Liou HC, Ling TY, Shen LJ. Development of a neuroprotective erythropoietin modified with a novel carrier for the bloodbrain barrier. Neurotherapeutics. $2020 \mathrm{Jul}$ 17(3):1184-96

$70 \mathrm{Im}$ JH, Yeo IJ, Hwang CJ, Lee KS, Hong JT. PEGylated erythropoietin protects against brain injury in the MCAO-induced stroke model by blocking NF- $\mathrm{kB}$ activation. Biomolecules Ther. 2020 Mar 1;28(2):152-62.

71 Weber A, Dzietko M, Berns M, FelderhoffMueser U, Heinemann U, Maier RF, et al. Neuronal damage after moderate hypoxia and erythropoietin. Neurobiol Dis. 2005 Nov; 20(2):594-600.

72 Ruan L, Wang B, ZhuGe Q, Jin K. Coupling of neurogenesis and angiogenesis after ischemic stroke. Brain Res. 2015 Oct 14;1623: 166-73. 
73 Chamorro Á, Dirnagl U, Urra X, Planas AM. Neuroprotection in acute stroke: targeting excitotoxicity, oxidative and nitrosative stress, and inflammation. Lancet Neurol. 2016 Jul; 15(8):869-81.

74 Wang R, Li J, Duan Y, Tao Z, Zhao H, Luo Y. Effects of erythropoietin on gliogenesis during cerebral ischemic/reperfusion recovery in adult mice. Aging Dis. 2017 Jul;8(4):410-9.

75 Tang Z, Sun X, Huo G, Xie Y, Shi Q, Chen S, et al. Protective effects of erythropoietin on astrocytic swelling after oxygen-glucose deprivation and reoxygenation: mediation through AQP4 expression and MAPK pathway. Neuropharmacology. 2013 Apr;67:8-15.

76 Tang Z, Sun X, Shi Q, Wang X, Xie Y, Huo G, et al. Beneficial effects of carbamylated erythropoietin against oxygen-glucose deprivation/reperfusion-induced astrocyte swelling: proposed molecular mechanisms of action. Neurosci Lett. 2012 Nov 14;530(1):23-8.

77 Wang L, Zhang Z, Wang Y, Zhang R, Chopp M. Treatment of stroke with erythropoietin enhances neurogenesis and angiogenesis and improves neurological function in rats. Stroke. 2004 Jul;35(7):1732-7.

78 Chan SJ, Love C, Spector M, Cool SM, Nurcombe V, Lo EH. Endogenous regeneration: engineering growth factors for stroke. Neurochem Int. 2017 Jul;107:57-65.

79 Sprigg N, Bath PM, Zhao L, Willmot MR, Gray LJ, Walker MF, et al. Granulocyte-colony-stimulating factor mobilizes bone marrow stem cells in patients with subacute ischemic stroke: the Stem cell Trial of recovery EnhanceMent after Stroke (STEMS) pilot randomized, controlled trial(ISRCTN 16784092). Stroke. 2006 Dec;37(12):2979-83.
80 Shyu WC, Lin SZ, Lee CC, Liu DD, Li H. Granulocyte colony-stimulating factor for acute ischemic stroke: a randomized controlled trial. CMAJ. 2006 Mar 28;174(7):92733.

81 Schabitz WR, Laage R, Vogt G, Koch W, Kollmar R, Schwab S, et al. AXIS: a trial of intravenous granulocyte colony-stimulating factor in acute ischemic stroke. Stroke. 2010 Nov; 41(11):2545-51.

82 Alasheev AM, Belkin AA, Leiderman IN, Ivanov RA, Isakova TM. Granulocyte-colonystimulating factor for acute ischemic stroke: a randomized controlled trial (STEMTHER). Transl Stroke Res. 2011 Sep;2(3):358-65.

83 Prasad K, Kumar A, Sahu JK, Srivastava MV, Mohanty S, Bhatia R, et al. Mobilization of stem cells using G-CSF for acute ischemic stroke: a randomized controlled, pilot study. Stroke Res Treat. 2011;2011:283473.

84 Moriya Y, Mizuma A, Uesugi T, Ohnuki Y, Nagata E, Takahashi W, et al. Phase I study of intravenous low-dose granulocyte colonystimulating factor in acute and subacute ischemic stroke. J Stroke Cerebrovasc Dis. 2013 Oct;22(7):1088-97.

85 Mizuma A, Yamashita T, Kono S, Nakayama T, Baba Y, Itoh S, et al. Phase II trial of intravenous low-dose granulocyte colony-stimulating factor in acute ischemic stroke. J Stroke Cerebrovasc Dis. 2016 Jun;25(6):1451-7.

86 England TJ, Abaei M, Auer DP, Lowe J, Jones DR, Sare G, et al. Granulocyte-colony stimulating factor for mobilizing bone marrow stem cells in subacute stroke: the stem cell trial of recovery enhancement after stroke 2 randomized controlled trial. Stroke. 2012 Feb; 43(2):405-11.
87 Ringelstein EB, Thijs V, Norrving B, Chamorro A, Aichner F, Grond M, et al. Granulocyte colony-stimulating factor in patients with acute ischemic stroke: results of the AX200 for ischemic stroke trial. Stroke. 2013 Oct;44(10):2681-7.

88 Philip M, Benatar M, Fisher M, Savitz SI. Methodological quality of animal studies of neuroprotective agents currently in phase II/ III acute ischemic stroke trials. Stroke. 2009 Feb;40(2):577-81.

89 Ehrenreich H, Hasselblatt M, Dembowski C, Cepek L, Lewczuk P, Stiefel M, et al. Erythropoietin therapy for acute stroke is both safe and beneficial. Mol Med. 2002 Aug;8(8):495505 .

90 Ehrenreich $\mathrm{H}$, Weissenborn $\mathrm{K}$, Prange $\mathrm{H}$, Schneider D, Weimar C, Wartenberg K, et al. Recombinant human erythropoietin in the treatment of acute ischemic stroke. Stroke. 2009 Dec;40(12):e647-56.

91 Unger EF, Thompson AM, Blank MJ, Temple R. Erythropoiesis-stimulating agents: time for a reevaluation. N Engl J Med. 2010 Jan 21; 362(3):189-92.

92 Steinbrook R. Erythropoietin, the FDA, and oncology. N Engl J Med. 2007 Jun 14;356(24): 2448-51.

93 Yip HK, Tsai TH, Lin HS, Chen SF, Sun CK, Leu S, et al. Effect of erythropoietin on level of circulating endothelial progenitor cells and outcome in patients after acute ischemic stroke. Crit Care. 2011;15(1):R40.

94 Tsai TH, Lu CH, Wallace CG, Chang WN, Chen SF, Huang CR, et al. Erythropoietin improves long-term neurological outcome in acute ischemic stroke patients: a randomized, prospective, placebo-controlled clinical trial. Crit Care. 2015 Feb 25;19:49. 